\title{
Financiamiento externo, deuda y transformación de la estructura productiva de El Salvador en la década de los ochenta: El papel de Estados Unidos.*
}

\author{
Herman Rosa y Alexander Segovia
}

\section{Introducción}

Durante la década de los ochenta, Estados Unidos ha venido articulando e impulsando en El Salvador un modelo de reordenamiento global de la economia que tiene como ejes fundamentales la reforma agraria y la promoción de exportaciones a terceros mercados. Dada la naturaleza de la crisis salvadoreña, dicho modelo aparece con una lógica esencialmente política, lo cual ha obligado a constantes readecuaciones y la incorporación de elementos muy particulares que lo diferencian del modelo relativamente ortodoxo que ha impulsado el Fondo Monetario Internacional y el Banco Mundial en otros paises del área.

Debido a que el modelo ha sido impulsado fundamentalmente con recursos provenientes de Estados Unidos que han asumido de manera creciente la forma de donaciones, la relación que en otros países del área aparece de manera clara entre deuda-financiamiento externo-ajuste extructural, ha sido sustituída en el caso de El Salvador por la relación financiamiento externo-ajuste. Además, es este mismo hecho to que explica el perfíl y la evolución tan particular que ha tenido la deuda externa salvadoreña, donde a la par de una cierta disminución en los últimos años se observa una creciente concentración en dos acreedores: AID y BID.

- Trabajo desarrollado para proyecto CRIES "Deuda Externa, Polltica Económica y Reinserción en Centroamérica y Panamán. 
Pero las transformaciones experimentadas por la estructura productiva no sólo han sido producto de este intento de reordenamiento estructural por parte de Estados Unidos. También han provocado transformaciones importantes, la crisis internacional y regional; y particularmente, la crisis intema global del país, así como algunas medidas de política económica. *

El estudio de estas transformaciones y del papel que en las mismas ha jugado Estados Unidos, la crisis misma y la política económica es el objeto de este trabajo.

\section{Crisis y deuda externa en EI Salvador}

Hasta principios de la década de los setenta El Salvador siguió a una politica de endeudamiento externo relativamente conservadora. No fue sino hasta el periodo posterior a 1973 que el endeudarniento externo experimentó un crecimiento importante empujado tanto por la crisis del sector externo derivada de los dos shocks petroleros, como por una política de gasto público más agresiva que la del periodo anterior.

Cuadro 1

El Salvador: Evoluclón y estructura de la deuda externa (1970-1987)

\begin{tabular}{|c|c|c|c|c|c|c|c|c|c|c|c|}
\hline & 1970 & 1973 & 1978 & 1980 & 1981 & 1982 & 1983 & 1984 & 1985 & 1986 & 1987p \\
\hline \multicolumn{12}{|c|}{ Monto en millones de dólares } \\
\hline Total deuda & 276 & 329 & 986 & 1192 & 1512 & 1716 & 1897 & 1981 & 2023 & 1980 & 1876 \\
\hline Pública & 94 & 133 & 339 & 475 & 653 & 816 & 995 & $\begin{array}{r}1086 \\
700\end{array}$ & 1190 & 1254 & 1308 \\
\hline Bancaria & 40 & 52 & 233 & 488 & 643 & 706 & 718 & 709 & 657 & 582 & 431 \\
\hline Privada & 142 & 144 & 413 & 229 & 217 & 193 & 185 & 186 & 175 & 144 & 137 \\
\hline $\begin{array}{l}\text { Corto plazo } \\
\text { My L plazo }\end{array}$ & $\begin{array}{r}39 \\
237\end{array}$ & $\begin{array}{r}53 \\
276\end{array}$ & $\begin{array}{l}316 \\
670\end{array}$ & $\begin{array}{l}270 \\
922\end{array}$ & $\begin{array}{r}346 \\
1166\end{array}$ & $\begin{array}{r}273 \\
1443\end{array}$ & $\begin{array}{r}154 \\
1743\end{array}$ & $\begin{array}{r}175 \\
1806\end{array}$ & $\begin{array}{r}154 \\
1869\end{array}$ & $\begin{array}{r}133 \\
1847\end{array}$ & $\begin{array}{r}72 \\
1803\end{array}$ \\
\hline
\end{tabular}

Estructura porcentual (\%)

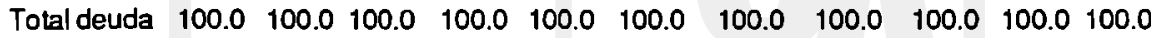

\begin{tabular}{|c|c|c|c|c|c|c|c|c|c|c|c|}
\hline Pública & 34.0 & 40.5 & 34.4 & 39.9 & 43.2 & 47.6 & 52.4 & 54.8 & 58.8 & 63.4 & 69.7 \\
\hline Banc & 14.5 & 15.7 & 23.7 & 40.9 & 42.5 & 41.2 & 37.8 & 35.8 & 32.5 & 29.4 & 23.0 \\
\hline rive & & 43.8 & 41. & 19. & 14.3 & 11 & 9.7 & 9.4 & 8.7 & 7.3 & \\
\hline $\begin{array}{l}\text { ort } \\
\text { Ay }\end{array}$ & $\begin{array}{l}4.2 \\
5.8\end{array}$ & $\begin{array}{l}16.0 \\
84.0\end{array}$ & $\begin{array}{l}32.1 \\
67.9\end{array}$ & $\begin{array}{l}22.6 \\
77.4\end{array}$ & $\begin{array}{l}22.9 \\
77.1\end{array}$ & $\begin{array}{l}15.9 \\
84.1\end{array}$ & $\begin{array}{r}8.1 \\
91.9\end{array}$ & $\begin{array}{r}8.8 \\
91.2\end{array}$ & $\begin{array}{r}7.6 \\
92.4\end{array}$ & $\begin{array}{r}6.7 \\
93.3\end{array}$ & \\
\hline
\end{tabular}

Fuenles: Banco Central de Reserva NOTA: Para los anos 1980-1987 la deuda bancarla Induye sólo la del Banco Central de Reserva, en tanlo para los afios anlerlores se Incluye lamblén la de la banca privada.

* Para electos del presente trabalo. el concepto de "iranslormaciones estructurales" hace relerencla a: modilicaciones en la estructura productiva, modilicaclones insthucionales, modíficaciones en el ilpo y las modalidades de la inserción exlerna, y redelinictones en las alianzas y iranslormaciones de grupos sociales. 
En efecto, en sólo cinco años (1974-1978) la deuda extema se triplicó (Cuadro 1). Si bien la mayor parte de la nueva deuda tuvo un carácter compensatorio, también fue significativo el endeudamiento del sector público para apoyar el proyecto de modernización económica que buscaba en este periodo la diversificación agricola, desarrollar mediante zonas francas un nuevo sector exportador a terceros mercados, y promover el desarrollo turístico del país. ${ }^{1}$

Respondiendo a las prioridades de ese proyecto, la nueva deuda del sector público (206 millones de dólares), se destinó en su mayor parte a infraestructura (energia, carreteras, puertos, telecomunicaciones) y proyectos de apoyo al sector agropecuario, pesca y agroindustria (ingenio Jiboa). En menor grado, parte del endeudamiento correspondió a inversión social.2

En los años ochenta, los factores fundamentales que marcan la evolución de la deuda son la grave crisis política del país y la respuesta norteamericana a dicha crisis. Asi, el fuerte endeudamiento ocurrido en los años 1980-81, fué fundamentalmente una respuesta a la fuga masiva de capitales ocurrida en ese período. Por otra parte, el desaceleramiento posterior de la deuda externa, asi como su reducción a partir de 1986, es producto del elevado nivel de donaciones oficiales provenientes de Estados Unidos (Cuadro Ii).

\section{Cuadro II \\ EI Salvador: Asistencla económica comprometida por AID como préstamos y donaciones}

(Años fiscales de Estados Unldos 1980-1989)

\begin{tabular}{|c|c|c|c|c|c|c|c|c|c|c|c|}
\hline & \multirow[b]{2}{*}{1980} & \multirow[b]{2}{*}{1981} & \multicolumn{2}{|c|}{$x+2 x \sqrt{2}$} & \multirow[b]{2}{*}{1984} & \multirow[b]{2}{*}{1985} & \multirow[b]{2}{*}{1986} & \multicolumn{2}{|l|}{ - } & \multicolumn{2}{|c|}{-} \\
\hline & & & 1982 & 1983 & & & & 1987 & 19880 & $1989 \mathrm{~s}$ & Total \\
\hline \multicolumn{12}{|c|}{ Millones de Dólares } \\
\hline $\begin{array}{l}\text { Préstamos } \\
\text { Donaciones } \\
\text { Total }\end{array}$ & $\begin{array}{l}40 \\
18 \\
59\end{array}$ & $\begin{array}{r}71 \\
35 \\
106\end{array}$ & $\begin{array}{r}71 \\
122 \\
193\end{array}$ & $\begin{array}{r}87 \\
175 \\
262\end{array}$ & $\begin{array}{r}81 \\
142 \\
223\end{array}$ & $\begin{array}{r}70 \\
359 \\
429\end{array}$ & $\begin{array}{r}52 \\
266 \\
318\end{array}$ & $\begin{array}{r}53 \\
416 \\
469\end{array}$ & $\begin{array}{r}35 \\
290 \\
325\end{array}$ & $\begin{array}{r}35 \\
258 \\
293\end{array}$ & $\begin{array}{r}595 \\
2081 \\
2675\end{array}$ \\
\hline \multicolumn{12}{|c|}{ Estructura Porcentual (\%) } \\
\hline $\begin{array}{l}\text { Préstamos } \\
\text { Donaciones } \\
\text { Total }\end{array}$ & $\begin{array}{r}69 \\
31 \\
100\end{array}$ & $\begin{array}{r}67 \\
33 \\
100\end{array}$ & $\begin{array}{r}37 \\
63 \\
100\end{array}$ & $\begin{array}{r}33 \\
67 \\
100\end{array}$ & $\begin{array}{r}36 \\
64 \\
100\end{array}$ & $\begin{array}{r}16 \\
84 \\
100\end{array}$ & $\begin{array}{r}16 \\
84 \\
100\end{array}$ & $\begin{array}{r}11 \\
89 \\
100\end{array}$ & $\begin{array}{r}11 \\
89 \\
100\end{array}$ & $\begin{array}{r}12 \\
88 \\
100\end{array}$ & $\begin{array}{r}22 \\
78 \\
100\end{array}$ \\
\hline
\end{tabular}

Fuente: 1. 1980-1983: Hemández Ramos, Rigoberto et. al. La politica Exterior norteamericana y su incidencia en la economía de El Salvador, Tesis, UCA, San Salvador, julio 1986. 2. 1984-1985: AlD, El Salvador - US Economic Asistance Program, Enero1987 3. 19861989: AID, Congressional Presentation Fiscal Years 1988, 1989. NOTAS: e. Estimación. s. Solicitud de Administración. En 1986 se incluyó la parte correspondiente al programa de Becas para la Paz según la fuente 2. 
La crisis política también presionó para que el sector privado liquidara sus compromisos con el exterior. Con ello su participación en la deuda disminuyó significativamente hasta caer por debajo del $10 \%$ de la deuda externa total. En contraste, el monto de la deuda del sector público aumentó de manera sostenida, elevando su participación en la deuda externa total a un $70 \%$ en 1987. Esta nueva deuda del sector público se diferencia del de los años setenta pues en gran medida ha respondido a las necesidades del proyecto contrainsurgente que Estados Unidos ha impulsado en el país.

Como se observa en el cuadro III, el endeudamiento con organismos oficiales creció extraordinariamente a principios de los ochenta, obedeciendo en parte a presiones de la Administración Reagan que buscó canalizar recursos al país por esa via, debido a la oposición que enfrentaba en el Congreso para otorgar asistencia masiva al país. Las presiones fueron exitosas en el-caso del FMI y del BID, pese a la resistencia de algunos aliados de Estados Unidos. ${ }^{3}$

Cuadro III

El Salvador: Estructura de la deuda externa por acreedor $(1978,1983,1986)$

\begin{tabular}{|c|c|c|c|c|c|c|}
\hline & 1978 & 1983 & 1986 & 1978 & 1983 & 1986 \\
\hline Total deuda externa & 986 & 1897 & 1980 & 100.0 & 100.0 & 100.0 \\
\hline \multicolumn{7}{|l|}{ Agencias internacionales } \\
\hline y gubernamentales & 372 & 1480 & 1686 & 37.8 & 78.0 & 85.2 \\
\hline USAID & 38 & 280 & 489 & 3.9 & 14.8 & 24.7 \\
\hline BID & 153 & 393 & 504 & 15.5 & 20.7 & 25.5 \\
\hline BIRF-AIF (Bco. Mundial) & 102 & 132 & 134 & 10.3 & 7.0 & 6.8 \\
\hline FMI & 17 & 169 & 91 & 1.7 & 8.9 & 4.6 \\
\hline Otra bilateral y multilater. & 63 & 506 & 468 & 6.4 & 26.7 & 23.6 \\
\hline Sector privado externo & 613 & 417 & 294 & 62.2 & 22.0 & 14.8 \\
\hline
\end{tabular}

Fuente: Banco Central de Reserva.

El creciente financiamiento proveniente de Estados Unidos y las presiones que éste ejerció en organismos multilaterales para lograr financiamiento adicional para el país, le fue dando a la deuda externa salvadorefía un pertíl por acreedor muy particular, pues creció el peso de los acreedores oficiales, sobre todo de AID y del BID. De hecho, la deuda 
con AID se multiplicó casi 13 veces entre 1978 y 1986 y la deuda con el BID también creció significativamente. Como resultado, a finales de 1986 la mital de la deuda externa se concentraba en ambas instituciones, participación que aumentó al $58 \%$, en 1987. El FMI, logra su participación más alta en 1983 y el Banco Mundial disminuyó paulatinamente la suya, pues fue hasta 1987 que otorgó el primer préstamo de esta década. ${ }^{4}$

\section{Cuadrolv \\ El Salvador: Préstamos otorgados por el Banco Interamericano de desarrollo} (1980-1985)

\begin{tabular}{|c|c|c|c|c|c|}
\hline $\begin{array}{l}\text { Préstamo } \\
\text { No. BID }\end{array}$ & Destino de los préstamos & Fecha & $\begin{array}{l}\text { Millones } \\
\text { dólares }\end{array}$ & $\begin{array}{l}\text { Plazol } \\
\text { gracia }\end{array}$ & $\begin{array}{l}\text { Comis/ } \\
\text { interes }\end{array}$ \\
\hline & Sector agricola & & $\underline{130.9}$ & Afíos & $\%$ \\
\hline 605/SF & Crédib agropecuario a pequefios productores & $11-09-80$ & $\overline{16.5}$ & $40 / 10$ & $0.50 / 1-2$ \\
\hline 642/SF & Crédito global al sector agropecuario relormado & $15-01-81$ & 40.5 & $40 / 10$ & $0.50 / 1-2$ \\
\hline $124 \pi \mathrm{TF}$ & Crédito global al secior agropecuario relormado & $15-01-81$ & 5.0 & $40 / 10$ & $0.50 / 1-2$ \\
\hline $705 / \mathrm{SF}$ & Desarrollo investigación y extensión agrlcola & $14-03-83$ & 12.9 & $40 / 10$ & $0.50 / 1-2$ \\
\hline 676/SF & Comercialización insumos y productos agricolas & 30-03-83 & 15.6 & $40 / 10$ & $0.50 / 1-2$ \\
\hline $480 / O C$ & Crédito agropecuario a medianos produclores & 14-02-85 & 11.4 & $20 / 3$ & $1.25 / \mathrm{var}$ \\
\hline \multirow[t]{2}{*}{$481 / O C$} & Crédito agropecuario a pequefios productores & $14-02-85$ & 29.1 & $20 / 3$ & $1.25 / \mathrm{var}$ \\
\hline & Sector industrlal (Bco. Central - BCF) & & 100.0 & & \\
\hline 429/OC & Reactivación del sector industrial - I Etapa & $10-11-82$ & 40.0 & & \\
\hline \multirow[t]{2}{*}{$478 / O C$} & Reactivación del sector industrial - II Etapa & $02-08-84$ & 60.0 & & \\
\hline & Fomento de exportaciones no tradicionales (BCR) & & 6.0 & & \\
\hline $36 / \mathrm{NF}$ & Crédito global rotatorio p/financiar exportaciones & $07-08-60$ & $\overline{1.0}$ & & \\
\hline 36ANF & Crédito global rotatorio p/financiar exportaciones & $05-03-81$ & 1.0 & & \\
\hline $36 \mathrm{BNF}$ & Crédito global rotatorio p/financiar exportaciones & $18-09-81$ & 1.0 & & \\
\hline $36 \mathrm{CNF}$ & Crédito global rotatorio P/financiar exportaciones & $17-06-82$ & 2.0 & & \\
\hline $381 / \mathrm{OC}$ & Crédito global rotatorio p/financiar exportaciones & $07-08-80$ & 0.5 & & \\
\hline \multirow[t]{2}{*}{ 3B1ANC } & Crédit global rotatorio p/financiar exportaciones & $0906-82$ & 0.5 & & \\
\hline & Sector de salud pública y ambiental & & 48.0 & & \\
\hline 604/SF & Mejoramiento de servicios de salud - IIEtapa & 24-03-80 & $\overline{27.0}$ & $40 / 10$ & $0.75 / 1-2$ \\
\hline $772 / \mathrm{SF}$ & $\begin{array}{l}\text { Programa de acueductos rurales - III Elapa } \\
\text { Sector onergla }\end{array}$ & $26-09-85$ & $\begin{array}{l}21.0 \\
66.0 \\
\end{array}$ & $40 / 10$ & $0.50 / 1-2$ \\
\hline $102 / \mathrm{IC}$ & Proyecto hidroelécrico San Lorenzo & $08-10-82$ & $\overline{49.5}$ & $40 / 10$ & $0.50 / 1-2$ \\
\hline $683 / \mathrm{SF}$ & $\begin{array}{l}\text { Proyecto hidroelécrico San Lorenzo } \\
\text { Infraestructura vlal }\end{array}$ & $08-10-82$ & $\begin{array}{l}16.5 \\
36.8\end{array}$ & $15 / 5$ & \\
\hline 665/SF & Construcción de caminos rurales en El Salvador & $06-01-83$ & 30.8 & $40 / 10$ & $0.50 / 1-2$ \\
\hline 453/OC & $\begin{array}{l}\text { Construcción puente San Marcos sobre rlo Lempa } \\
\text { Estudlos de preinversión }\end{array}$ & $17-05-84$ & $\begin{array}{r}6.0 \\
12.0 \\
\end{array}$ & $15 / 4.5$ & $1.25 / \mathrm{var}$ \\
\hline 596/SF & Programa de preinversión (FOSEP I) & 24-03-80 & 4.5 & $40 / 10$ & $0.50 / 1-2$ \\
\hline \multirow[t]{2}{*}{$732 / \mathrm{SF}$} & Programa de preinversión - II Etapa & $20-01-84$ & 7.5 & $40 / 10$ & $0.50 / 1-2$ \\
\hline & Total & & 399.7 & & \\
\hline
\end{tabular}

Fuente: Banco Interamericano de Desarollo y Ministerio de Hacienda de El Salvador.

NOTA: Fechas son las de emisión o contrato en EI Salvador, excepto en el caso de los préstamos administrados por el Banco Central donde las fechas corresponden a la de aprobación por el BID. 
Como se observa en el Cuadro IV, gran parte de los préstamos otorgados por el BID en el periodo 1980-85, tuvieron un carácter "notradicional", pues se vieron enmarcados en la lógica del proyecto contrainsurgente que Estados Unidos impulsa en El Salvador, tal es el caso de los préstamos para apoyar la reforma agraria, reponer infraestructura dañada por el sabotaje de la guerrilla (Puente San Marcos en Río Lempa), y construir caminos rurales en zonas conflictivas (el noreste del país). Otros, han buscado reactivar el sector industrial mediante lineas de crédito, asi como apoyar la promoción de exportaciones a terceros mercados.

De hecho, los préstamos "tradicionales" que suman $\$ 155$ millones, representan menos del $40 \%$ del total contratado en este período, el cual asciende a casi 400 millones de dólares. ${ }^{5}$ Recien en 1987, el BID se concentra nuevamente en préstamos del tipo "tradicional" cuando otorga tres préstamos por un monto total de $\$ 189$ millones de dólares. ${ }^{6}$

\section{Cuadro V}

El Salvador: Préstamos otorgados por la Agencla para el Desarrollo Internacional AID (1980-1987)

\begin{tabular}{|c|c|c|c|c|c|}
\hline $\begin{array}{l}\text { Préstamo } \\
\text { AID }\end{array}$ & Destino del préstamo & Focha & $\begin{array}{l}\text { Millones } \\
\text { dólares }\end{array}$ & $\begin{array}{l}\text { Plazo/ } \\
\text { gracla }\end{array}$ & $\begin{array}{l}\text { Comlsión } \\
\text { interes }\end{array}$ \\
\hline $\begin{array}{l}024 y 025 \\
026 y 027 \\
028 \\
029 \\
030 \\
031 \\
032 \\
033 \\
023-F\end{array}$ & $\begin{array}{l}\text { Generación de empleo en sector püblico } \\
\text { Mejoramiento de comunidades marginales } \\
\text { Crédilos de la relorma agraria. } \\
\text { Organización y adiestramiento de relorma agraria } \\
\text { Apoyo al sector privado II } \\
\text { Pestauración servicios públicos } \\
\text { Apoyo a implementación de reforma agraria } \\
\text { Revitalización sistema salud I } \\
\text { Desarrollo pequeflo producior en áreas rurales } \\
\text { Convenio de productos agricolas PL-480-1980 } \\
\text { Convenio de productos agricolas PL-480- } 1981 \\
\text { Convenio de productos agricolas PL-480-1982 } \\
\text { Convenio de productos agricolas PL-480-1983 } \\
\text { Convenio de productos agricolas PL-480-1984 } \\
\text { Convenio de productos agricolas PL-480-1985 } \\
\text { Convenio de productos agricolas PL-480-1986 } \\
\text { Convenio de productos agricolas PL-480-1987 } \\
\text { Total }\end{array}$ & $\begin{array}{l}25-03-80 \\
01-04-80 \\
07-07-80 \\
30-09-80 \\
26-07-81 \\
19-11-81 \\
21-09-83 \\
23-09-83 \\
26-02-85 \\
18-06-80 \\
22-01-81 \\
15-03-82 \\
15-12-82 \\
01-12-83 \\
01-11-84 \\
20-12-85 \\
22-05-87\end{array}$ & $\begin{array}{r}39.9 \\
11.0 \\
81.5 \\
11.7 \\
24.9 \\
13.4 \\
38.5 \\
23.4 \\
1.0 \\
3.0 \\
24.5 \\
19.9 \\
39.0 \\
49.0 \\
49.0 \\
46.0 \\
42.0 \\
517.7\end{array}$ & $\begin{array}{l}25 / 9.5 \\
25 / 9.5 \\
25 / 9.5 \\
25 / 9.5 \\
40 / 9.5 \\
40 / 9.5 \\
40 / 9.5 \\
40 / 9.5 \\
25 / 9.5 \\
15.5 / 5 \\
15.5 / 5 \\
15.5 / 5 \\
15.5 / 5 \\
15.5 / 5 \\
15.5 / 5 \\
15.5 / 5 \\
15.5 / 5\end{array}$ & $\begin{array}{l}0.0 / 2 \\
0.0 / 2 \\
0.0 / 2-3 \\
0.0 / 2-3 \\
0.0 / 2 \\
0.0 / 2 \\
0.0 / 2-3 \\
0.0 / 2-3 \\
0.0 / 2-3 \\
0.0 / 2-3 \\
0.02-3 \\
0.02-3 \\
0.02-3 \\
0.0 / 2-3 \\
0.022-3 \\
0.02-3 \\
0.0 / 2-3\end{array}$ \\
\hline
\end{tabular}

Fuente: Ministerio de Hacienda de El Salvador y AID.

Los préstamos otorgados por AID en el periodo 1980-87 (Cuadro V), se destinaron sobre todo a la reforma agraria ( $\$ 132$ millones) y a la estabilización económica y social. El $53 \%$ del monto total contratado, son 
préstamos para importar alimentos (PL -480, Título I), y después de 1984 son prácticamente el único tipo de préstamos, pues la mayor parte de la asistencia económica se comprometió como donaciones, al grado de representar en los años fiscales $1987-88$, un $89 \%$ del total de dicha asistencia (Cuadro II).

En el marco de esta dinámica del endeudamiento externo tan particular si bien el servicio de la deuda se incrementó a partir de 1984, hasta superar el $45 \%$ de las exportaciones en el período $1984-1987$, se aprecia que el monto destinado a intereses que alcanzó un máximo de 117 millones en 1982 se ha mantenido desde entonces en unos 100 millones de dólares (Cuadro IV); comportamiento que se vincula al hecho de que la deuda externa de El Salvador se ha concentrado crecientemente en fuentes oficiales, donde prevalecen bajas tasas de interés y largos periodos de amortización.

\section{Cuadro VI}

El Salvador: Evolución del servicio de la deuda externa (1977-1987)

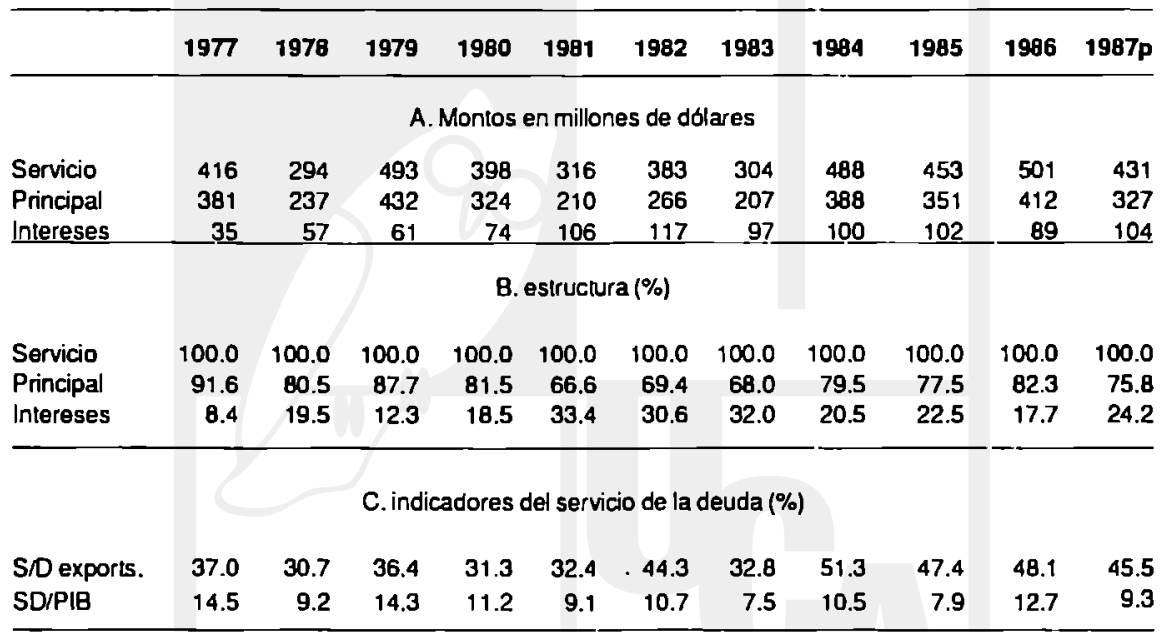

Fuente: Banco Central de Reserva.

El análisis realizado hasta aquí, si bien muestra la enorme incidencia que Estados Unidos ha tenido en la evolución de la deuda externa de El Salvador en los ochenta y en la forma tan particular que adopta su perfil nos dice muy poco del programa económico que Estados Unidos ha venido impulsando en El Salvador. Ello es asi porque la asistencia económica norteamericana asume fundamentalmente la forma de donaciones. De alli que para desentrafiar dicho programa es necesario un aná- 
lisis en detalle del programa completo de asistencia económica, tal como se intenta a continuación.

\section{Asistencia económica y modelo de transformación estructural dé Estados Unidos en El Salvador.}

\subsection{Destlno de la asistencia económica}

La asistencia económica comprometida por Estados Unidos a EI Salvador superó los $\$ 2400$ millones de dólares en el periodo 1980-1988, habiéndose destinado el $86 \%$ de tales recursos al esfuerzo de estabilización económica y social. No obstante, a la transformación estructural también se destinó una cantidad de recursos lo suficientemente significativos (\$ 344 millones) como para incidir directamente en dicha transformación, asi como para crear condiciones que permitan avanzar más rápidamente en el futuro. (Cuadro VII).

\section{Cuadro VII}

El Salvador: Destino de la asistencia económica comprometida por AID (Años fiscales de Estados Unidos 1980-1987)

\begin{tabular}{|c|c|c|c|c|c|c|c|c|c|c|}
\hline & 1860 & 1881 & 1882 & 1883 & 1094 & 1805 & 1886 & $1987^{1}$ & 19082 & Tolal \\
\hline & \multicolumn{10}{|c|}{ (Millonea de dolarea) } \\
\hline $\begin{array}{l}\text { Estabillzación económica } \\
\text { Apoyo a balanza de pagos } 3 \\
\text { Restauración servicios públicos } \\
\text { Planil. de politica económica }\end{array}$ & $\begin{array}{l}5.4 \\
3.0 \\
1.5 \\
0.9\end{array}$ & $\begin{array}{r}62.0 \\
62.0 \\
0.0 \\
0.0\end{array}$ & $\begin{array}{r}141.2 \\
127.3 \\
13.4 \\
0.5\end{array}$ & $\begin{array}{r}174.6 \\
159.0 \\
14.6 \\
1.0\end{array}$ & $\begin{array}{r}155.3 \\
149.0 \\
5.0 \\
1.3\end{array}$ & $\begin{array}{r}300.4 \\
274.0 \\
25.0 \\
1.4\end{array}$ & $\begin{array}{r}213.3 \\
191.0 \\
20.0 \\
2.3\end{array}$ & $\begin{array}{r}263.4 \\
241.2 \\
20.0 \\
2.2\end{array}$ & $\begin{array}{r}219.5 \\
199.5 \\
19.0 \\
1.0\end{array}$ & $\begin{array}{r}1534.9 \\
1406.0 \\
118.5 \\
10.5\end{array}$ \\
\hline $\begin{array}{l}\text { Eslabilizadon eocial } \\
\text { Desastre, vivlenda desplazados } \\
\text { Empleo y programas especiales } \\
\text { Salud } \\
\text { Educación } \\
\text { Planilicación de población } \\
\text { Relorma Judicial y política }\end{array}$ & $\begin{array}{r}25.2 \\
9.1 \\
14.2 \\
0.9 \\
0.0 \\
0.9 \\
0.0\end{array}$ & $\begin{array}{r}33.5 \\
17.6 \\
13.7 \\
0.5 \\
0.0 \\
1.8 \\
0.0\end{array}$ & $\begin{array}{r}29.8 \\
14.2 \\
13.5 \\
0.0 \\
0.1 \\
1.8 \\
0.2\end{array}$ & $\begin{array}{r}49.6 \\
26.2 \\
0.9 \\
17.0 \\
0.3 \\
1.9 \\
3.4\end{array}$ & $\begin{array}{r}27.8 \\
15.4 \\
0.9 \\
6.1 \\
0.3 \\
1.9 \\
3.2\end{array}$ & $\begin{array}{r}79.4 \\
41.3 \\
2.8 \\
13.9 \\
9.1 \\
6.2 \\
6.0\end{array}$ & $\begin{array}{r}56.2 \\
14.5 \\
2.7 \\
16.3 \\
16.0 \\
6.7 \\
0.0\end{array}$ & $\begin{array}{r}191.0 \\
169.5 \\
2.7 \\
9.2 \\
5.3 \\
1.3 \\
3.0\end{array}$ & $\begin{array}{r}43.2 \\
11.9 \\
1.6 \\
17.9 \\
7.4 \\
1.1 \\
3.3\end{array}$ & $\begin{array}{r}535.7 \\
319.7 \\
53.0 \\
81.7 \\
38.6 \\
23.6 \\
19.1\end{array}$ \\
\hline $\begin{array}{l}\text { Transformación estructural } \\
\text { Relorma agrarla } \\
\text { Seclor privado exportador } \\
\text { Pequena empresa } \\
\text { Educación para el cambio }\end{array}$ & $\begin{array}{r}28.0 \\
22.0 \\
0.0 \\
6.0 \\
0.0\end{array}$ & $\begin{array}{r}10.8 \\
10.5 \\
0.0 \\
0.3 \\
0.0\end{array}$ & $\begin{array}{r}22.3 \\
20.4 \\
0.0 \\
1.5 \\
0.4\end{array}$ & $\begin{array}{r}37.7 \\
36.3 \\
0.0 \\
1.0 \\
0.4\end{array}$ & $\begin{array}{r}40.0 \\
32.4 \\
3.0 \\
4.2 \\
0.4\end{array}$ & $\begin{array}{r}49.0 \\
26.9 \\
10.6 \\
8.1 \\
3.4\end{array}$ & $\begin{array}{r}48.2 \\
22.4 \\
16.0 \\
2.8 \\
6.9\end{array}$ & $\begin{array}{r}54.0 \\
27.1 \\
20.4 \\
1.8 \\
4.7\end{array}$ & $\begin{array}{r}53.9 \\
19.7 \\
22.2 \\
6.5 \\
5.5\end{array}$ & $\begin{array}{r}343.7 \\
217.7 \\
72.2 \\
32.2 \\
21.6\end{array}$ \\
\hline Tolal & 58.5 & 106.2 & 193.2 & 261.9 & 223.1 & 428.8 & 317.7 & 508.3 & 316.5 & 2414.3 \\
\hline
\end{tabular}

\section{(Eatructura porcentual)}

\begin{tabular}{|c|c|c|c|c|c|c|c|c|c|c|}
\hline Eatabilizadón económice & 9.2 & 58.4 & 73.0 & 66.7 & 69.6 & 70.0 & 67.1 & 51.8 & 69.3 & 63.6 \\
\hline Estabilizadón social & 43.0 & 31.5 & 15.4 & 19.0 & 12.5 & 18.5 & 17.7 & 37.6 & 13.6 & 22.2 \\
\hline $\begin{array}{l}\text { Eatabillzación es tructural } \\
\text { Relorma agraria } \\
\text { Sector privado exponador } \\
\text { Pequeña empresa } \\
\text { Eduacion para el camblo }\end{array}$ & $\begin{array}{r}47.8 \\
37.6 \\
0.0 \\
10.2 \\
0.0\end{array}$ & $\begin{array}{r}10.1 \\
9.9 \\
0.0 \\
0.2 \\
0.0\end{array}$ & $\begin{array}{r}11.5 \\
10.6 \\
0.0 \\
0.8 \\
0.2\end{array}$ & $\begin{array}{r}14.4 \\
13.9 \\
0.0 \\
0.4 \\
0.1\end{array}$ & $\begin{array}{r}17.9 \\
14.5 \\
1.3 \\
1.9 \\
0.2\end{array}$ & $\begin{array}{r}11.4 \\
6.3 \\
25 \\
1.9 \\
0.8\end{array}$ & $\begin{array}{r}15.2 \\
7.1 \\
5.1 \\
0.9 \\
2.2\end{array}$ & $\begin{array}{r}10.6 \\
5.3 \\
4.0 \\
0.4 \\
0.9\end{array}$ & $\begin{array}{r}17.0 \\
6.2 \\
7.0 \\
21 \\
1.7\end{array}$ & $\begin{array}{r}14.2 \\
9.0 \\
3.0 \\
1.3 \\
0.9\end{array}$ \\
\hline Tolal & 100.0 & 100.0 & 100.0 & 100.0 & 100.0 & 100.0 & 100.0 & 100.0 & 100.0 & 100.0 \\
\hline
\end{tabular}

Fuenle: Elaboración propia sobre le base de la Tabla 1 del anexo dende ce indican las proyectas induldas en cada rubro. NOTAS: 1. Estimación. 2

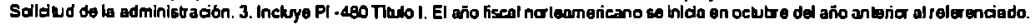


Los ejes centrales de este programa de transformación estructural son la reforma agraria y la promoción de exportaciones a terceros mercados. Complementariamente, ante al elevado desempleo, se promueve la pequefia empresa urbana y rural. Si bien la reforma agraria es la componente principal del programa en términos de recursos comprometidos, los destinados al desarrollo del sector exportador, han crecido rápidamente a partir del año fiscal 1984, superando los destinados a impulsar la pequena empresa e incluso los destinados a la reforma agraria, para el año fiscal 1988. (Cuadro VII).

Pero el programa de asistencia va más allá de lo que muestra el Cuadro VII, pues los recuros comprometidos por AID que alli se clasifican como apoyo a balanza de pagos generan moneda local, ${ }^{7}$ cuyo destino también debe acordarse con AID. EI Cuadro VIII, por ejemplo, muestra el programa de moneda local de 1987, cuyo monto equivalía al $29 \%$ del presupuesto general del gobierno de 1987 que fue 3473 milones de colones.

\section{Cuadro VIII}

El Salvador: Programa de moneda local de AID para 1987

\begin{tabular}{l|rrr}
\hline Origen de la moneda local (millones y porcentajes) & colones & dólares & $\%$ \\
PI -480 título año fiscal 1987 & 175.0 & 35.0 & 17.5 \\
Fondo de apoyo económico (ESF) año fiscal 1987 & 785.0 & 157.0 & 78.5 \\
Arrastre fondo de apoyo económico (ESF) año liscal 1986 & 20.0 & 4.0 & 2.0 \\
Recursos del gobierno de El Salvador & 20.0 & 4.0 & 2.0 \\
\hline
\end{tabular}

\begin{tabular}{lrrr} 
Deslino de la moneda local (millones y porcentajes) & colones & dólares & $\%$ \\
\hline Restauración Servicios Públicos & 70.5 & 14.1 & 7.1 \\
Comisión Nacional de Restauración de Areas (CONARA) & 51.0 & 10.2 & 5.1 \\
Otros proyectos de estabilización social & 78.7 & 15.7 & 7.9 \\
Apoyo institucional & 6.1 & 1.2 & 0.6 \\
Proyectos de desarrollo agropecuario & 12.7 & 2.5 & 1.3 \\
Apoyo a sector privado (Banco Central de Reserva) & 302.0 & 60.4 & 30.2 \\
Contrapartida nacional de proyectos de AID & 82.8 & 16.6 & 8.3 \\
Contrapartida nacional de proyeclos del BID & 47.1 & 9.4 & 4.7 \\
Contrapartida proyectos otros donantes & 31.9 & 6.4 & 3.2 \\
Fondo para proyectos de inversión & 80.0 & 16.0 & 8.0 \\
Apoyo al presupuesto ordinario y de inversión del gobiemo & 210.0 & 42.0 & 21.0 \\
Gastos de operación y apoyo de la misión local de AID & 25.0 & 5.0 & 2.5 \\
Fondo de reserva & 2.3 & 0.5 & 0.2 \\
\hline Total & & & \\
\hline
\end{tabular}

Fuente: Elaboración propia sobre la base de Memorandums de entendimiento AID-Gobierno de EI Salvador. 
Obsérvese que también en el caso del programa de moneda local, la mayoria de los recursos son absorbidos por la estabilización económica y social. No obstante, una fracción no despreciable corresponde al esfuerzo de transformación estructural ya sea en fondos de contrapartida de los proyectos de AID para tal fin, o mediante las líneas de crédito del Banco Central para el sector privado exportador.

En cuanto a la promoción de exportaciones, es necesario destacar que la opción preferencial de AID en el caso de EI Salvador, al menos inicialmente, ha sido impulsarla basándose en la diversificación agricola, y no tanto en la maquila. Esta preferencia resulta lógica si se toma en cuenta el papel central que juega el sector nural en el estallido de la crisis salvadorefia y el hecho de que resulta aparentemente más simple desarrollar nuevas exportaciones de productos agricolas que de productos industriales, donde la inversión extranjera juega un papel central. No obstante, también en esta última línea se están haciendo esfuerzos importantes.

\section{CuadrolX}

Proyectos de AID en El Salvador para promover las exportaciones no tradicionales

(Miles de dólares comprometidos en años fiscales 1984-1988)

\begin{tabular}{|c|c|c|c|c|c|c|c|}
\hline Tilulo del proyeclo & No. & 1984 & 1985 & 1986 & 19871 & 19881 & Total \\
\hline $\begin{array}{l}\text { Manejo de recursas aculferos } \\
\text { Desarrollo de "agribusiness" }\end{array}$ & $\begin{array}{l}d 303 \\
d 327\end{array}$ & & 3500 & 8220 & $\begin{array}{l}4300 \\
2000\end{array}$ & $\begin{array}{l}2724 \\
5000\end{array}$ & $\begin{array}{r}18744 \\
7000\end{array}$ \\
\hline Recuperación industrial & d287 & 3000 & 6460 & 7000 & 8000 & 5000 & 29460 \\
\hline Parques industriales/infraestructura & d323 & & & & & 1000 & 1000 \\
\hline Parques industriales/infraestructura & p323 & & & & & 5000 & 5000 \\
\hline Capacit. p/productividad y competitividad & d315 & & & & 2000 & 3450 & 5450 \\
\hline Empresarios Juveniles OPG & d311 & & 300 & 350 & 3000 & & 3650 \\
\hline Fortalecimiento FUSADES & d316 & & 370 & 475 & 1100 & & 1945 \\
\hline Total & & 3000 & 10630 & 16045 & 20400 & 22174 & 72249 \\
\hline
\end{tabular}

Fuente: Elaboracbón propla scbre la base de Tabla No. 3 en Anexo. NOTAS: 1 . Estlmación. 2 Solicitud de la administrackón. La letra d o p en el nümero del proyecto indica donación o préstamo.

Los proyectos concretos para impulsar la promoción de exportaciones se muestran en cuadro IX. Para el desarrollo de nuevos productos agricolas de exportación AID ha comprometido fondos para dos proyectos, el de manejo de aguas que según AID financia infraestructura para cosechar "productos de exportación no tradicionales como frutas, vegetales y camarones"8 y a partir del año fiscal 1987 el proyecto de "agribusiness" que financiaria a "productores y comercializadores que 
se involucren en el procesamiento y mercadeo de exportación de productos no tradicionales." Los objetivos de largo plazo en el caso del agro serian un crecimiento del $4 \%$ anual en el valor real de la producción agricola y del $15 \%$ anual en la producción de productos agrícolas de exportación no tradicionales. ${ }^{9}$

En el sector industrial, el proyecto de recuperación industrial con el cual AID inició sus esfuerzos de promoción de exportaciones ha generado según AID casi $\$ 15$ millones de dólares en divisas y más de 5000 empleos. ${ }^{10}$ Asimismo, el proyecto de parques industriales para el que se comprometieron fondos a partir del año fiscal 1988 busca reactivar las zonas francas en el pais. El proyecto de "Capacitación para la productividad y competitividad, a su vez financia la "capacitación de trabajadores y administradores de empresas privadas involucradas en la exportación."11 A mediano plazo, AID contempla expandir la capacitación técnica y vocacional en los niveles secundario y post-secundario.

\subsection{Evolución del programa de transformación estructural}

Como se ha visto, la asistencia económica que Estados Unidos ha otorgado a El Salvador ha permitido impulsar no sólo un ambicioso programa de estabilización económica y social, sino también un programa de transformación estructural de mediano-largo plazo, el cual ha evolucionado en consonancia con las readecuaciones de la estrategia norteamericana para enfrentar la crisis en El Salvador y Centroamérica.

\section{Fase I: La Reforma Agraria como eje central (1980-1982)}

A raíz de la explosión de la guerra civil y con el propósito de restar apoyo al movimiento insurgente, se impulsaron en El Salvador algunas reformas, la más importante de las cuales corresponde al programa de reforma agraria, decretada en marzo de 1980 en el marco de un pacto político patrocinado por Estados Unidos entre la Fuerza Armada y el Partido Demócrata Cristiano. Esta participación de Estados Unidos marcaria el inicio de un proceso de internalización de la politica norteamericana en El Salvador como nunca antes había ocurrido.

En el periodo 1980-1982, donde la estrategia norteamericana tenía esencialmente un carácter político-militar, la asistencia económica buscó esencialmente lograr un minimo de estabilización social que permitiera consolidar el proceso político que Estados Unidos impulsaba. En ese marco el proyecto de transformación estructural se centra en el impulso a la reforma agraria.

Así como todavia en 1983, AID explicitamente afirmaba que tos cuatro objetivos prioritarios de su estrategia hasta Marzo 1984 (fecha fijada para elecciones presidenciales), eran: a) apoyar la estabilización eco- 
nómica (incluyendo una reducción de los elevados niveles de desempleo); b) la implementación de la reforma agraria; c) la asistencia humanitaria a los desplazados por el conflicto; y d) la expansión de los servicios de planificación familiar. ${ }^{12}$

Al evaluar los resultados de la reforma agraria seis afios después, una misión interagencial de las Naciones Unidas, concluia que a pesar de que la reforma agraria habia beneficiado al $22 \%$ de la población rural $(95,200$ familias) la mayor parte de la población rural continuaba "viviendo en una situación donde la pobreza y la miseria dominan su vida día a dia".13 Este sector que comprendía 200,000 familias sin tierra representaba según el estudio el $51 \%$ de las familias rurales.

Nos obstante, la reforma agraria complejizó la estructura social en el campo, pues a la par de las familias sin tierra aparecen 31,500 familias agrupadas en las cooperativas formadas al expropiarse las propiedades con extensiones superiores a las 500 hectáreas (Fase I de la reforma agraria), que el informe de Naciones Unidas consideraba que podría convertirse "en un sector claramente privilegiado en el medio rural". 14

La limitada cobertura que ha tenido la reforma agraria, impone un límite importante a la misma, pues el dique de contención que representa el desarrollo de un sector privilegiado en el agro, puede ser arrasado rápidamente por la enormidad de las necesidades insatisfechas del resto de la población.

\section{Fase II: Impulso inical al proyecto exportador (1983-1985)}

La reforma agraria por si misma era insuficiente para darle salida a la crisis en El Salvador favorable a Estados Unidos, especialmente cuando su profundidad era tal que resultaba imposible la reactivación de la economia a pesar del abundante financiamiento externo. Por otra parte, las reformas impulsadas por Washington habian generado fuertes contradicciones con los grupos dominantes tradicionales, dificultando el trabajo a través de las gremiales que esos grupos dominaban. Todo ello apuntaba a la necesidad de un reordenamiento mucho más radical que permitiera darle salida a la crisis global que se enfrentaba.

Es en ese marco que resulta crucial la promoción y creación con financiamiento de AID en abril de 1983, de una nueva gremial, la Fundación Salvadorena para el Desarrollo Económico y Social (FUSADES) como un organismo privado que posibilitaria la internalización del proyecto económico norteamericano y la unificación del sector privado para superar la crisis de hegemonia en torno a un nuevo proyecto económico que se centraria en la promoción de exportaciones a terceros mercados.

Dos años más tarde, FUSADES saca a la luz pública con gran publicidad su propuesta para "un nuevo modelo económico" cuyo eje central 
será la promoción de exportaciones a terceros mercados basándose para ello en un diagnóstico de la crisis económica en El Salvador que privilegia el condicionamiento que el sector externo ha impuesto al crecimiento económico. El carácter temporal del financiamiento externo extraordinario que el pais ha estado recibiendo, obliga según FUSADES a redefinir el modelo pues bajo el esquema existente las necesidades de recursos externos resultarian imposibles de lograr. De alli que el logro de metas razonables de empleo y crecimiento exige que se impulse un modelo exportador. ${ }^{15}$

Este proyecto exportador se impulsaria inicialmente en el marco de la Iniciativa de la Cuenca del Caribe (ICC), anunciada en febrero de 1982 (que con modificaciones sustanciales por el Congreso, entró en vigencia en enero de 1984), cuyo rasgo más importante, retomado luego con matices por el Informe Kissinger, es la idea de promover el desarrollo futuro de estas economías sobre la base de su reorientación hacia la exportación de productos no tradicionales.

La ICC, sin embargo, compartia la misma concepción ortodoxa del resto de la política' económica internacional de la administración Reagan y es necesario la publicación del Informe Kissinger, para readecuar la estrategia económica y se comience a impulsar más decididamente. El Informe Kissinger proponía una reactivación inicial de la economia centroamericana sobre las mismas bases anteriores, revivir el Mercado Común Centroamericano y un ajuste estructural relativamente lento que permitiera reorientar las economias centroamericanas hacia los mercados extrarregionales, todo ello apoyado con una masiva asistencia financiera de ocho mil millones de dólares y descansando en AID para la coordinación del programa, que al parecer se pensaba podia sustituir al FMI.

Como medidas concretas el Informe Kissinger proponía revitalizar las exportaciones tradicionales y el comercio intrarregional, apoyar la pequeña empresa altamente absorbedora de mano de obra y programas de desarrollo agricolas acelerados orientados hacia el sector productor de alimentos de consumo que permitieran aumentar su producción y reducir las importaciones de los mismos. A mediano plazo, también se proponía el desarrollo de un importante sector industrial de exportación a terceros mercados. ${ }^{16}$

En la práctica se ignoró la recomendación específica del Informe relativa a revitalizar el Mercado Común Centroamericano mediante el financiamiento de las duedas acumuladas entre los distintos países. Al respecto, en un informe de la Contraloria de Estados Unidos sobre los programas regionales se indica que los fondos solicitados para este propósito (95 milones de dólares en el año fiscal 1985 y 16 millones adi- 
cionales en el año siguiente), no se comprometieron obedeciendo a la conclusión de un estudio de AID de mayo 1985 que planteaba que financiar tales deudas sería contrapuducente pues surgirian de nuevo y además desestimularian la realización de las reformas cambiarias necesarias para reactivar el comercio intrarregional e incrementar las exportaciones extrarregionales. ${ }^{17}$

\section{Fase III: La promoción de exportaciones cono eje central del Programa de Transformación Estructural (1986-88)}

El período 1986-88 corresponde a una tercera fase del programa de cambio estructural de AID, donde básicamente se retoma la propuesta de promover las exportaciones a terceros mercados, supeditándose de manera cada vez más agresiva a ello todo lo demás.

Esta posición respecto a la promoción de exportaciones, la expresó claramente la Administración norteamericana en marzo 1987, en un documento (Reporte No. 162) donde se presentaba al Congreso una propuesta para "financiar totalmente" las recomendaciones del Informe Kissinger mediante la extensión de la asistencia económica a Centroamérica hasta $1992,{ }^{18}$ donde explícitamente se aprecia una readecuación importante de la estrategia económica original que se proponia en el Informe Kissinger, a pesar de afirmarse que los cambios afectaban sólo el ritmo del programa y no su contenido. ${ }^{19}$

El Reporte No. 162, mencionaba asi explícitamente que los niveles de asistencia propuestos se basaban en el supuesto de que "los gobiernos centroamericanos implementarán medidas económicas para promover el crecimiento basado en las exportaciones (export-led growth) y reformas estructurales esenciales", entendiéndose por tales fundamentalmente la reducción del déficit fiscal y el mantenimiento de un régimen cambiario "apropiado".

Además, se ignoró la recomendación del Informe Kissinger de revitalizar el comercio intrarregional aduciendo que en tanto el crecimiento económico futuro de la región provendría predominantemente de las exportaciones a mercados extrarregionales, la preocupación principal era asegurar que las monedas de la región estuviesen a tono con el régimen monetario mundial.20

De manera menos perceptible en dicho reporte se da también una reorientación del programa de desarrollo agricola con los pequeños productores, pues mientras el Informe Kissinger hacia énfasis en el estimulo a la producción de alimentos para el consumo local, 21 ahora resultaba que, al convertirse a la promoción de exportaciones en el criterio ordenador fundamental, se pretendia al igual que en el caso de la pequeña 
empresa industrial orientar todos los esfuerzos hacia tal fin. Mediante la búsqueda de mecanismos que permitiesen:

a los pequeños agricultores integrarse al esfuerzo para producir exportaciones agricolas no tradicionales como productores independientes, y para que las industrias pequeñas y medianas logren expandir sus metas más allá de los reducidos mercados nacionales. ${ }^{22}$

Coincidiendo con esta nueva fase del programa de transformación estructural de Estados Unidos en el pais, el gobierno salvadoreño desplegó importantes esfuerzos tendientes a incentivar las exportaciones no tradicionales a terceros mercados. Una primera línea de acción fue la modificación y modernización del marco institucional que rige las actividades de exportación, tales como la emisión en 1987 de una nueva Ley de Fomento de Exportaciones ${ }^{23}$ y la aprobación en mayo de 1988 de la Ley de Fomento y Garantia de la Inversión Extranjera. Una segunda línea de acción ha sido el relanzamiento de las zonas francas. ${ }^{24}$ Además, se han otorgado importantes incentivos cambiarios ${ }^{25}$ y se han ampliado las líneas de crédito destinadas al fomento de actividades de exportación no-tradicional.

\section{Fase IV: Privatización y Liberalización (1989- )}

Actualmente, el programa de AID en El Salvador está entrando a lo que podria ser su cuarta fase, donde los esfuerzos de promoción de exportaciones via proyectos se complementaría con un esfuerzo de privatización tanto de empresas estatales como de las mismas cooperativas de la reforma agraria, y con la promoción de algunas medidas de política económica más en la linea de los tradicionales programas de estabilización y ajuste. En la propuesta de asistencia presentada ante el Congreso para el año fiscal 1989 por AID se plateaba que:

en el nivel macroeconómico AID estimulará al gobierno de El Salvador para que continúe reduciendo el déficit del sector público, revise el régimen de tipos de interés y canalice más crédito a los sectores productivos. En el nivel sectorial, AID promoverá cambios de política tales como la eliminación de subsidios a productos y la privatización de empresas propiedad del estado. ${ }^{26}$

Para impulsar la privatización, AID propuso un nuevo proyecto en su programa de asistencia del año fiscal 1989 y urgia al gobierno de El Salvador para que adoptara "legislación que le diera la propiedad individual a los miembros de las cooperativas del sector reformado".27 De esta manera AID busca involucrar a los beneficiarios de la reforma agraria "en una nueva estrategia de crecimiento agricola que pone más énfasis en la actividad comercial con inversionistas del sector privado."28 
Esta nueva fase, naturalmente que requerirá la aplicación de una condicionalidad más estricta, por lo que resulta útil analizar como ha evolucionado la condicionalidad aplicada a la asistencia económica en el caso de El Salvador.

\subsection{Evolución de la condicionalidad de la asistencia}

El pausado ritmo de ajuste propuesto por el Informe Kissinger (que suponía una baja condicionalidad en el otorgamiento de la asistencia económica), así como el nuevo papel de AID como formulador de programas de estabilización y ajuste propuesto para el Informe, si bien resultaba congruente con la visión del Departamento de Estado norteamericano no fue inicialmente compartido por otras Agencias federales, particularmente el Departamento del Tesoro y la Oficina de Administración y Presupuesto.

Según el reporte de la Contraloría General de los Estados Unidos de julio de 1985, que evaluaba la asistencia económica a EI Salvador y Honduras, ${ }^{29}$ existian divergencias entre las distintas agencias federales en cuanto a la prioridad de las reformas económicas en estos dos paises y en cuanto al grado de presión que debia ejercerse para que se realizaran dichas reformas, o sea en cuanto al grado de condicionalidad bajo el cual debia otorgarse la ayuda económica, asi como en cuanto al papel del FMI. ${ }^{30}$

Por un lado, el Departamento de Estado insistía en que no se podian exigir cambios en la política económica a costa de los objetivos políticos y de seguridad de los Estados Unidos, como por ejemplo, exigiendo reformas económicas impopulares que socavasen la estabilidad política. En cambio, el Departamento del Tesoro y la Oficina de Administración y Presupuesto, consideraban necesario que se presionase con mayor fuerza por reformas de política económica. ${ }^{31}$

Criticando la posición del Departamento de Estado, la Oficina de Administración y Presupuesto, afirmaba que las consecuencias de posponer las reformas económicas podia ser tan desestabilizante políticamente como retener la ayuda, pues en la medida en que se retrasasen las reformas, más radicales tenian que ser cuando se aplicasen en el futuro.32 A su vez, el Departamento del Tesoro llegaba al extremo de afirmar que tales reformas no sólo eran importantes para la efectividad de la ayuda económica norteamericana, sino que eran "el objetivo fundamental de la ayuda norteamericana". ${ }^{33}$

Mostrando una desconfianza en la capacidad de AID de formular programas de reformas económicas, estos dos organismos insistirian en la necesidad de acudir nuevamente a los programas del FMI, no sólo porque tiene más recursos y experiencia que AID, sino también porque ello 
permitiria la captación de recursos de otras fuentes (Tesoro), 34 y ejercer presión sobre cuestiones delicadas de reforma económica, algo en lo que Estados Unidos por sí mismos estaba muy limitado (Oficina de Presupuesto). ${ }^{35}$

Estas contradicciones sin duda obligaron al Departamento de Estado norteamericano a ejercer mayores presiones por cambios en la política económica en El Salvador, asi como a revaluar, al menos retóricamente, el papel que el FMI podía jugar en este país. Así, en un documento de mayo de 1984, AID recomendaba al gobierno salvadorefio, la negociación de un nuevo tratado con el FMI. ${ }^{36}$ Por otra parte, en respuesta a las criticas contenidas en el reporte de la Contraloría, citado anteriormente, AID respondió que si bien la ayuda para los años fiscales 84 y 85 no se condicionó a acuerdos con el FMI, el objetivo había sido alcanzar un marco de política macroeconómica que llevase a la estabilización y al crecimiento de largo plazo y que, a la vez, facilitase el logro de acuerdo con el FMI. ${ }^{37}$ Resulta significativo, sin embargo, que desde el 1983 no se ha dado ningún nuevo acuerdo con dicho organismo.

No obstante, esas criticas harían mella y desde 1986 se muestra un creciente endurecimiento de las posiciones de AID en EI Salvador y como se vió, un mayor énfasis en la promoción de exportaciones a terceros mercados de lo que se hacia en el Informe Kissinger. Fue así como el gobierno salvadoreño finalmente decretó en enero de 1986 la devaluación que AID habia previsto para finales de 1984 . $^{38}$

En 1987, la posición se endureció aun más al cuestionarse en Washington la capacidad del gobierno salvadoreño para articular una política económica adecuada. ${ }^{39}$

Como resultado y en marcado contraste con la situación anterior, AID comienza a retener los desembolsos de la asistencia económica comprometida a El Salvador, en tanto el gobierno no presentara un programa de política económica aceptable a dicho organismo y ejecutara medidas específicas, tales como una nueva devaluación. Además, por primera vez en un convenio por 42 millones de dólares, firmado en mayo de 1987 , se incluyó una cláusula según la cual el gobierno norteamericano "declararia caducado cualquier convenio firmado con el gobierno de El Salvador, si los programas para los cuales se ha concedido determinado préstamo o donación de recursos económicos no se realizan tal como han sido elaborados, presentados y aprobados".40

De manera poco usual, al presentar la memoria de labores del tercer año de gestión de su gobierno, el primero de junio de 1987, el Presidente Duarte denunció públicamente las presiones para devaluar y apeló al Presidente Reagan para que se continuara con los desembolsos de la asistencia económica, a la vez que anunciaba una promoción vigorosa 
de las exportaciones no tradicionales sin necesidad de devaluar. Esta posición proclive a la promoción de exportaciones contrasta con la posición del periodo anterior donde se le daba una baja prioridad en los planes económicos del gobierno, a pesar del interés de AID y de FUSADES.

La mayor condicionalidad de la asistencia otorgada al gobierno salvadorefio refleja que la pugna interburocrática al interior de la administración norteamericana se habia saldado. El nuevo consenso respecto a la condicionalidad, se dió en la linea de la de la Oficina de Administración y Presupuesto, pues como se aprecia en el reporte No. 162 , se retoma su planteamiento al afirmarse que si bien:

La implementación de .. reformas estructurales presenta un dilema para gobiernos democráticos frágiles (pues) en el corto plazo, tales acciones imponen penurias económicas sobre algunos grupos de cuyo apoyo dependen los gobiernos .. en el largo plazo, la omisión en corregir los problemas estructurales subyacentes sólo conduce al empeoramiento de las condiciones económicas para todo el país. Por lo tanto, la asistencia económica de los Estados Unidos debe condicionarse a la implementación de las reformas necesarias, pues de lo contrario se necesitarán niveles de asistencia cada vez más elevados simplemente para evitar el deterioro económico adicional. ${ }^{41}$

De esta manera, a la vez que se pertilaba mejor el programa económico norteamericano para la región se intentaba endurecer la condicionalidad de la asistencia otorgada, algo que al parecer también se vincula con la necesidad de lograr una mayor eficacia de la asistencia económica, especialmente cuando ésta ya no puede seguir creciendo como antes, dado los recortes que ha venido sufriendo el presupuesto global de asistencia de Estados Unidos. ${ }^{42}$

Sin embargo, en el contexto de la crisis global que enfrenta El Salvador, las medidas de ajuste tienen que tomar muy en cuenta las implicaciones sociales de su ejecución. Ello explica porqué mientras en la propuesta inicial de FUSADES, se decia muy poco respecto al problema de las necesidades básicas insatisfechas de la mayoría de la población salvadorefia, a lo largo de 1986, dicha institución desarrolla estudios en torno a ese problema, a fin de incorporar una "política social" en su modelo, pues como decia FUSADES; "no se trata sólo de llenar necesidades básicas sino de lograr una estabilidad socio-económica y política que permita salir de la crisis". 43

Esta preocupación por lo "social" se manifestó también en 1987. cuando FUSADES propone la adopción gradual de su propia adaptación "a la neoliberal" del esquema alemán de la posquerra que sus proponentes han bautizado con el nombre de "economia social de mercado".44 
Resulta muy significativo que el planteamiento de FUSADES con sus posteriores readecuaciones (promoción de exportaciones, economia social de mercado, atención a las necesidades básicas y ataque a la pobreza crítica, etc.) fue recogido casi literalmente en la plataforma programática del partido ARENA presentada de cara a las elecciones presidenciales de 1989.45 *

\section{Crisis, política económica y transformaciones de la estructura pro- ductiva en los ochenta}

A continuación se analizan los efectos que sobre la estructura productiva salvadorefía han ocasionado la crisis global del país, asi como las medidas de política económica adoptadas. Concretamente, interesa destacar las transformaciones que han ocurrido, así como los cambios que están en proceso, y que pueden eventualmente desembocar en transformaciones importantes a mediano y largo plazo. Los sectores objeto de estudio son el agropecuario, el industrial y el sector externo.

\subsection{El sector agropecuario}

Durante la década de los ochenta, el sector agropecuario ha sufrido transformaciones y cambios importantes en su estructura y en su composición, los cuales han estado asociados a por lo menos tres tipos de factores: la crisis interna global del país, especialmente los efectos directos e indirectos de la guerra; las medidas de política económica adoptadas para enfrentar los desequilibrios macroeconómicos; $y$, finalmente, las políticas dirigidas especiticamente hacia el sector, especialmente la reforma agraria y la nacionalización del comercio exterior del café y el azúcar, y las tendientes a diversificar la producción agropecuaria de exportación.

El resultado más importante de la conjugación de los elementos anteriores, ha sido, por un lado, una crisis sin precedentes de la agricultura tradicional de exportación, y a la vez, una incipiente pero significativa diversificación de la producción agricola de exportación.

\section{Evolución reciente}

Durante el periodo 1979-1987, la producción agropecuaria experimentó una fuerte contracción, especialmente entre los años 1979-1983 cuando se redujo en un $16 \%$. El grueso de la caida se originó en la producción agrícola de exportación tradicional y en la ganadería, rubros que en conjunto representaban alrededor del $60 \%$ del sector en 1979.

Como resultado de esta evolución, la composición del producto sectorial ha sufrido cambios significativos, destacándose la pérdida de la importancia relativa de los productos de exportación, en beneficio de los 
granos básicos y la avicultura. Efectivamente, el subsector "productos principales de exportación", que incluye el café, algodón y la cafia de azúcar, disminuyó su participación dentro de la agricultura en un $8.5 \%$, producto fundamentalmente de la drástica disminución del algodón, que redujo su participación de $7.9 \%$ en 1979 a solamente un $1.8 \%$ en 1987 . Contrariamente, los subsectores silvicultura, pesca, apicultura y avicultura experimentaron una evolución favorable durante el periodo, lo que les permitio aumentar su participación dentro del producto agropecuario en términos absolutos y relativos (Tabla No. 2 en anexo).

La fuerte contracción experimentada por el sector agropecuario no se ha traducido en una pérdida relativa de su importancia dentro de la economia, ya que el resto de sectores en su conjunto, y especialmente la manufactura y el comercio, tuvieron un desenvolvimiento peor aun. Esto explica porque dicho sector ha mantenido su participación en alrededor de un $25 \%$ dentro del producto interno bruto, y ha aumentado su participación a más del $70 \%$ dentro de las exportaciones totales.

\section{Desencadenamiento y profundización de la crisis de la agricultura tra- dicional de exportación}

El efecto más importante de la crisis internacional e interna del pais y de las medidas globales de política económica sobre el sector agricola, ha sido el desencadenamiento de una crisis sin precedentes del sector agrícola tradicional de exportación, especialmente del café y del algodón.

La drástica reducción de los precios internacionales de dichos productos coincidió en nuestro país con la explosión de la crisis interna y la generalización del conflicto armado, lo que profundizó la crisis del sector agropecuario en general, y la del sector exportador tradicional en particular. Posteriormente, el sector sufrió los efectos de las medidas adoptadas por el gobierno para hacer frente a la crisis económica.

El resultado de todo lo anterior fue una disminución drástica de la producción agrícola de exportación, explicada fundamentalmente en el caso del café por una disminución de la productividad, y en el caso del algodón por la disminución de casi el $90 \%$ del área sembrada. En efecto, la producción promedio de las últimas tres cosechas de café ha sido interior en más de un millón de quintales a la obtenida en los primeros años de la década. (Cuadro $X$ ).

En el caso del algodón, la producción ha pasado de promedios superiores a los 4 millones de quintales registrados a finales de los setenta, a menos de 300 mil quintales durante los últimos tres años. Esta caida de la producción sumada a la disminución de los precios internacionales 
explica la drástica disminución a la mitad de las exportaciones de café y la casi desaparición de las de algodón. (Cuadro XI)

\section{Cuadro X \\ El Salvador: Evolución de la producción agricola \\ (cosechas 1978/79-1987/88) \\ (Miles de quintales)}

\begin{tabular}{|c|c|c|c|c|c|c|c|c|c|c|}
\hline & $78 / 70$ & $78 R 0$ & e0/81 & $81 / 82$ & $82 / 83$ & 03/64 & $84 / 85$ & $85 / 86$ & $86 / 87$ & $87 / 68$ \\
\hline $\begin{array}{l}\text { Producios de } \\
\text { exportacion } \\
\text { cale } \\
\text { algodón } \\
\text { canáde azucar }\end{array}$ & $\begin{array}{r}3913 \\
4408 \\
3322\end{array}$ & $\begin{array}{l}4307 \\
4047 \\
2564\end{array}$ & $\begin{array}{l}3850 \\
2542 \\
2263\end{array}$ & $\begin{array}{l}3800 \\
2465 \\
2372\end{array}$ & $\begin{array}{r}3790 \\
885 \\
3016\end{array}$ & $\begin{array}{r}2930 \\
656 \\
3400\end{array}$ & $\begin{array}{r}3552 \\
660 \\
3455\end{array}$ & $\begin{array}{r}2908 \\
408 \\
3647\end{array}$ & $\begin{array}{r}3100 \\
234 \\
3269\end{array}$ & $\begin{array}{r}3500 \\
209 \\
3269\end{array}$ \\
\hline $\begin{array}{l}\text { Granos báslcos } \\
\text { malz } \\
\text { Irljol } \\
\text { aroz } \\
\text { maldillo }\end{array}$ & $\begin{array}{r}11021 \\
933 \\
1105 \\
3518\end{array}$ & $\begin{array}{r}11365 \\
1011 \\
1266 \\
3486\end{array}$ & $\begin{array}{r}11448 \\
867 \\
1320 \\
3041\end{array}$ & $\begin{array}{r}10868 \\
832 \\
1090 \\
2950\end{array}$ & $\begin{array}{r}9000 \\
830 \\
770 \\
2700\end{array}$ & $\begin{array}{r}9633 \\
918 \\
940 \\
2277\end{array}$ & $\begin{array}{r}11462 \\
1056 \\
1377 \\
3054\end{array}$ & $\begin{array}{r}10769 \\
751 \\
1497 \\
2883\end{array}$ & $\begin{array}{l}9500 \\
1000 \\
1155 \\
2924\end{array}$ & $\begin{array}{r}12576 \\
531 \\
914 \\
564\end{array}$ \\
\hline
\end{tabular}

Fuente: Banco Central de Racerva de $\mathrm{E}$ Salvador.

Contrariamente a lo sucedido con el café y el algodón, la caña de azúcar ha tenido una evolución relativamente favorable durante el período de crisis. Ello se debe en gran parte a que sólo una pequeña parte del área cañera ha sido afectada por la guerra. Además, ha mantenido su rentabilidad gracias a la cuota en el mercado de precios preferenciales de los Estados Unidos y al apoyo decidido del gobierno.

En el caso del café, la incidencia de la guerra ha sido fundamentalmente de manera indirecta, mediante la generación de un clima de inseguridad y desconfianza entre los caficultores. Esta situación ha sido reconocida por la mayoria de estudios. EI BID por ejemplo, señala que la principal consecuencia de guerra ha sido el aumento de la incertidumbre económica, y agrega que debido a la inseguridad de las zonas rurales, "muchos caficultores descuidaron la administración de las plantaciones, especialmente en cuanto a las tareas de cultivo como poda de sombras y de cafetos, fertilización y limpieza".46

Por su parte, la reducción del áréa algodonera, especialmente durante los primeros años de la crisis se explica fundamentalmente por la guerra. Esto se debe a que la zona algodonera más importante se encuentra en el oriente del pais, uno de los principales teatros de operaciones militares. Un elemento adicional que ha contribuido a que los efectos del conflicto se hayan hecho sentir más en el caso del algodón, es que se trata de un cultivo anual, situación que lo hace más susceptible a las expectativas destavorables generadas por aquel.

- El segundo factor que explica la caida de la producción agricola de exportación es la disminución de la rentabilidad de los cultivos, producto 
Cuadro XI

El Salvador: Evolución de las exportaciones (1979-1987)

(Millones de dólares)

\begin{tabular}{|c|c|c|c|c|c|c|c|c|c|}
\hline & 1979 & 1980 & 1981 & 1982 & 1983 & 1984 & 1985 & 1986 & $1987^{1}$ \\
\hline \multicolumn{10}{|l|}{ Exportaciones } \\
\hline de bienes (FOB) & 1132 & 1075 & 798 & 700 & 758 & 726 & 659 & 755 & 592 \\
\hline tradicionales & 799 & 739 & 551 & 482 & 545 & 499 & 520 & 586 & 387 \\
\hline café & 675 & 624 & 458 & 403 & 438 & 444 & 458 & 439 & 352 \\
\hline algodón & 85 & 87 & 55 & 45 & 55 & 9 & 29 & 5 & 2 \\
\hline azúcar & 27 & 13 & 15 & 16 & 40 & 26 & 23 & 25 & 12 \\
\hline camarón & 12 & 15 & 23 & 18 & 12 & 20 & 10 & 17 & 21 \\
\hline no tradic. al MCCA & 267 & 296 & 206 & 174 & 165 & 157 & 96 & 91 & 120 \\
\hline $\begin{array}{l}\text { no tradic. al resto } \\
\text { del mundo }\end{array}$ & 67 & 40 & 41 & 44 & 48 & 70 & 80 & 78 & 85 \\
\hline \multicolumn{10}{|l|}{ Exportaciones } \\
\hline de bienes (FOB) & 100.0 & 100.0 & 100.0 & 100.0 & 100.0 & 100.0 & 100.0 & 100.0 & 100.0 \\
\hline tradicionales & 70.6 & 68.7 & 69.0 & 68.9 & 72.0 & 68.8 & 78.9 & 77.6 & 65.4 \\
\hline calé & 59.6 & 58.0 & 57.4 & 57.5 & 57.8 & 61.2 & 69.5 & 71.4 & 59.5 \\
\hline algodón & 7.5 & 8.1 & 6.9 & 6.5 & 7.3 & 1.3 & 4.4 & 0.6 & 0.4 \\
\hline azúcar & 2.4 & 1.2 & 1.9 & 2.3 & 5.3 & 3.6 & 3.5 & 3.4 & 2.0 \\
\hline camarón & 1.1 & 1.4 & 2.9 & 2.6 & 1.5 & 2.8 & 1.5 & 2.3 & 3.5 \\
\hline no tradic. al MCCA & 23.5 & 27.5 & 25.8 & 24.9 & 21.8 & 21.7 & 14.5 & 12.1 & 20.3 \\
\hline del mundo & 5.9 & 3.7 & 5.1 & 6.2 & 6.3 & 9.6 & 12.1 & 10.3 & 14.4 \\
\hline
\end{tabular}

Fuente: Banco Central de Reserva de El Salvador. $1 /$ Cifras preliminares.

tanto de la caída de los precios internacionales como de la política económica, particularmente de las políticas adoptadas para hacerle frente a la crisis del sector externo.

- La política económica seguida por los diferentes gobiernos para enfrentar la crisis global ha castigado duramente a los cultivos tradicionales de exportación, ya que ha buscado transferir recursos de dicho sector al resto de la economia, principalmente a través de la política cambiaria y la política fiscal. El caso más evidente lo constituye la política cambiaria. El tipo de cambio altamente sobrevaluado al que se liquidaban las divisas provenientes de las exportaciones de café y algodón durante el período 1982-1985 redujo considerablemente la capacidad financiera de los productores.

Debido a la crisis de divisas ocurrida en los primeros años de la década, el Banco Central de Reserva autorizó un mercado paralelo de cambio para un sector reducido de las operaciones con el exterior, que fue ampliado constantemente. El sistema dual de cambios en el período 1982 a 1985 estuvo formado por un tipo de cambio oficial de 2.50 colones por 
un dólar por el pago de la deuda externa, la importación de bienes esenciales (combustibles, medicinas, alimentos básicos, fertilizantes y otros) y la exportación de productos tradicionales (café, algodón, azúcar y camarón); y un tipo de cambio paralelo de fluctuación libre administrado conjuntamente por los bancos comerciales y el Banco Central, cuya cotización del promedio anual de venta alcanzó un nivel de 3.91 colones por dólar en 1982 y se elevó progresivamente hasta alcanzar 4.3 colones por dólar a finales de 1985.47

Esta política incidió negativamente en las exportaciones tradicionales, especialmente el café y el algodón, cuya liquidación se hacia al tipo de cambio oficial ( 2.50 colones), no obstante que los costos de producción absorbian la inflación interna y los efectos del tipo de cambio paralelo. En el caso del café esta política se mantuvo hasta enero de 1986, cuando finalmente se procedió a unificar el tipo de cambio.

Un estudio realizado por AID para el algodón en 1984, cuando el tipo de cambio para las exportaciones del cultivo era de 2.50 colones por dólar, refleja claramente el impacto de tal politica. Según los cálculos, en las condiciones existentes en aquel momento con respecto al área total de siembra, rendimientos promedio, costos de producción, de procesamiento y precios internacionales de venta, la única manera en la que el productor podía tener utilidades era liquidando la cosecha al tipo de cambio del mercado paralelo de ese entonces, de 3.85 colones por dólar. ${ }^{48}$

Por otra parte, en el caso particular del café, el gobierno ha recurrido a otro mecanismo para transferir recursos; nos referimos al impuesto a la exportación del grano. Este gravemen, vigente desde 1950, estableció una escala progresiva en función del precio FOB de exportación. Se suponia que, para los costos de producción de la época en que se estableció, un precio de exportación en exceso de 40 dólares generaba ganancias excesivas para el productor. Con el transcurso del tiempo sin embargo, los costos de producción subieron notablemente, pero no se cambió la estructura dle impuesto. Como parte de las medidas de estabilización adoptadas en enero de 1986, se afiadió al impuesto un recargo adicional del $15 \%$ sobre el precio en exceso de 135.0 dólares por quintal, que lo hizo aun más oneroso para los productores.

Si a lo anterior añadimos los efectos colaterales derivados del conflicto armado y de la implementación de las reformas estructurales, especialmente la reforma agraria y la nacionalización del comercio exterior del café y del azúcar, resulta comprensible porque la producción agricola de exportación se encuentra en una crisis como la que hemos detallado.]

Por su importancia, merece destacar la gravedad de la crisis de la caficultura. Según el Ministerio de Planificación, en 1986, el $46.6 \%$ del 
área cultivada de café $(123,705$ manzanas) se encontraba en total o parcial abandono, que incluye aquellos casos de abandono financiero en los que los propietarios no realizan inversiones, aunque si recogen total o parcialmente la cosecha mediante arreglos especiales con los trabajadores agrícolas. ${ }^{49}$

Este alto porcentaje de fincas en abandono muestra claramente la gravedad de la crisis de la caficultura salvadorefia, la cual ha dejado de ser una crisis coyuntural, y se ha convertido en una crisis de dimensiones estructurales. 50

\section{La incipiente diversificación agropecuaria}

El otro fenómeno importante que ha ocurrido en el sector agropecuario durante la presente década, y especialmente a partir de 1984, es el proceso, todavia en ciernes, de una diversificacióin de la producción, especialmente la de productos agricolas no tradicionales de exportación, y de consumo interno. Aunque no existen estadisticas confiables al respecto, las pocas evidencias sugieren que a estas alturas del proceso ya se han logrado algunos resultados, los cuales de consolidarse, podrian traer conformaciones importantes en la estructura agropecuaria.

Dado que no existen estadísticas a nivel nacional que permitan dimensionar la magnitud del grado de diversificación alcanzada hasta la fecha, optamos por analizar el comportamiento experimentado por los productos no tradicionales en el sector reformado, ya que éste se ha privilegiado para impulsar la estrategia.

Tal como lo muestra el Cuadro XII, los esfuerzos de diversificación en sector reformado han sido importantes. Durante el año agricola 1986/1987 el área cultivada de "otros rubros" fue de 24, 191 hectáreas, cifra que representa el $7.2 \%$ dle área total del sector de la reforma agraria.

\section{Cuadro XII}

Area cultivada de "otros rubros" por los beneficiarios de la reforma agraria (Año agricola 1986/1987)

\begin{tabular}{lrcr}
\hline Rubros & decreto 154-842 & decreto 207 & total reforma agraria \\
\hline sandia & & & \\
y melones & 1.474 & 3.169 & 4.643 \\
otros & 13.211 & 6.337 & 19.548 \\
total & 14.685 & 9.506 & 24.191 \\
\hline
\end{tabular}

Fuente: PERA, MAG. 
Es importante destacar la naturaleza distinta de la diversificación según la fase que se trate. Mientras las cooperativas pertenecientes a la Fase I se han concentrado en los productos agrícolas no tradicionales de exportación, los pequefios productores pertenecientes a la tercera fase (Decreto 207) han optado por los productos agricolas no tradicionales destinados básicamente al consumo interno.

Efectivamente, el incremento significativo del área cultivada de productos no tradicionales ocurrido durante los últimos años en las cooperativas de la Fase I se explica fundamentalmente por el incremento sustancial del área destinada a productos como ajonjoli, okra, cardamomo, sandia, melón, los cuales han sido destinados principalmente para la exportación (Cuadro XIII). Al parecer, la producción de dichos cultivos ha beneficiado a las cooperativas, ya que según un estudio reciente, los realizan a través de contratos con companias nacionales y extranjeras, cubriéndose de esta manera de todo riesgo. 51

Con respecto a los productores individuales del Decreto 207 éstos han realizado enormes esfuerzos por diversificar su producción, especialmente de productos no tradicionales de consumo interno tales como tomate, cebolla, papa, pepino, rábano, papaya y otros, lo cual, según el MAG, "denota el esfuerzo de las familias de los beneficiarios del 207, por aumentar el ingreso y reducir el riesgo en sus cosechas tradicionales".52 Pese a no contar con datos confiables, la poca evidencia sugiere que durante los últimos años ha habido un incremento importante de la producción nacional de dichos cultivos, lo que estaría explicando la caída significativa de las importaciones de dichos productos. ${ }^{53}$

A nuestro entender, este proceso de diversificación de la producción agricola, especialmente la de exportación, va a cobrar fuerza durante los próximos años. Los incentivos, crediticios, cambiarios y fiscales que se brindan a los empresarios que se dediquen a la exportación de produtos agrícolas no tradicionales, están dando ya sus resultados. El indicador más evidente de este proceso es la gran cantidad de empresas que actualmente se dedican a tal actividad. Según datos del Miinisterio de Comercio Exterior, a mediados de 1988, 24 empresas agroindustriales dedicadas a la exportación de produtos no tradicionales se habian acogido a la ley de fomento de exportaciones.

\subsection{El sector industrial}

El sector industrial ha sido sin duda, el sector más perjudicado por la crisis global del pais en la década de los ochenta. El impacto de la crisis se ha traducido en un deterioro sin precedentes de la base industrial del pais, la cual es más débil en términos absolutos y ciertamente en tér- 


\section{Cuadro XIII}

El Salvador: Evoluclón de la superflele y producclón cultlvada de "otros productos" en forma colectiva en las cooperativas de la primera etapa de la reforma agraria, según rubros prInclpales.

(Años agricolas)

\begin{tabular}{|c|c|c|c|c|c|c|}
\hline \multirow[b]{2}{*}{ Rubros } & \multicolumn{3}{|c|}{ Superficle } & \multicolumn{3}{|c|}{ Producclón (CO) } \\
\hline & $\begin{array}{l}\text { Promedio } \\
1980 / 85\end{array}$ & 1985/86 & $1986 / 87$ & $1984 / 85$ & $1985 / 86$ & $1986 / 87$ \\
\hline \multicolumn{7}{|c|}{$\begin{array}{l}\text { 1. Productos existentes } \\
\text { antes del proceso }\end{array}$} \\
\hline $\begin{array}{l}\text { Henequén } \\
\text { Coco } \\
\text { Bálsamo } \\
\text { Marafión } \\
\text { Cltricos }\end{array}$ & $\begin{array}{r}2.936 \\
3.132 \\
\text { n.d. } \\
1.493 \\
454\end{array}$ & $\begin{array}{r}2.749 \\
3.255 \\
359 \\
1.515 \\
606\end{array}$ & $\begin{array}{r}2.719 \\
2.879 \\
466 \\
1.066 \\
626\end{array}$ & $\begin{array}{r}42.050 \\
9.842 .833 \\
102 \\
8.019 \\
20.861\end{array}$ & $\begin{array}{r}25.050 \\
22.304 .086 \\
64 \\
8.972 \\
47.335\end{array}$ & $\begin{array}{r}30.107 \\
20.556 .987 \\
55 \\
8.661 \\
33.988\end{array}$ \\
\hline \multicolumn{7}{|c|}{ 2. Nuevos producios } \\
\hline $\begin{array}{l}\text { Ajonjoll } \\
\text { Cardamomo } \\
\text { Okra } \\
\text { Kenal } \\
\text { Musaceas } \\
\text { Melón } \\
\text { Sandia } \\
\text { Otros }\end{array}$ & $\begin{array}{l}664 \\
\text { n.d. } \\
212 \\
\text { n.d. } \\
632 \\
390 \\
500 \\
961\end{array}$ & $\begin{array}{l}974 \\
500 \\
302 \\
280 \\
975 \\
618 \\
557 \\
991\end{array}$ & $\begin{array}{r}1.342 \\
426 \\
416 \\
377 \\
1.057 \\
664 \\
696 \\
1.523\end{array}$ & $\begin{array}{r}2.509 \\
927 \\
44.839 \\
8.608 \\
238.247 \\
101.246 \\
83.324 \\
\text { n.d. }\end{array}$ & \begin{tabular}{r|}
5.786 \\
620 \\
58.968 \\
10.482 \\
144.766 \\
146.502 \\
120.312 \\
n.d.
\end{tabular} & $\begin{array}{r}14.654 \\
71 \\
69.464 \\
9.407 \\
136.886 \\
111.402 \\
135.464 \\
\text { n.d. }\end{array}$ \\
\hline Total & 11.374 & 13.680 & 14.257 & & & \\
\hline
\end{tabular}

Fuerte: PERA-MAG.

minos relativos que en la década de los setenta, y muestra además un agravamiento de sus debilidades estructurales.

\section{Evoluclón reciente}

Hasta 1982 el sector industrial fue el sector más afectado por la crisis global del pais. Durante el periodo 1979-82 dicho sector se contrajo a una tasa promedio anual superior al $9 \%$, experimentando una caida acumulada superior al $30 \%$. A partir de 1983, comenzó a mostrar signos de recuperación, tendencia que se consolidó en el período 1984-87, en el cual creció a una tasa promedio anual de $2.6 \%$.

Son varios los factores que explican el comportamiento anterior. El primero de ellos tuvo que ver con la inseguridad que prevaleció en esa época. Hay que recordar que en el periodo 1979-1980, el enfrentamiento 
político-militar se dió esencialmente en las principales ciudades del país, y particularmente en la zona metropolitana de San Salvador, centro industrial del país. La toma de fábricas, el sabotaje directo a instalaciones industriales, asi como el secuestro y asesinato de algunos empresarios, fueron elementos que provocaron el cierre temporal o definitivo de muchas fábricas, la salida del pais de muchos empresarios, y la postergación de los planes de inversión.54

Además de lo anterior, hay que sefialar las serias dificultades que experimentó la industria en dicho periodo derivadas de la falta de divisas necesarias para efectuar las importaciones que requería el aparato industrial salvadoreño, el cual como se sabe, es altamente dependiente de insumos y materias primas importadas. Un factor adicional que contribuyó a profundizar la crisis del sector fue el debilitamiento del MERCOMUN. Como resultado, las exportaciones industriales experimentaron una sensible caida, pasando de representar un $35 \%$ del total en 1978 , a sólo un $23 \%$ en 1985.

A partir de 1983, la situación del sector industrial cambió significativamente: el conflicto político militar se desarrrolla fundamentalmente en las áreas rurales, lo cual se traduce en una mayor seguridad para los empresarios, y el sector recibe un tratamiento especial de parte del gobierno a fin de lograr su reactivación.

En julio de 1981 fue creada la línea de crédito para capital de trabajo estructural con una cartera inicial de $\mathbf{5 2 . 3}$ millones de colones, la cual estaba agotada casi totalmente en 1983. En enero de este último año, se constituyó el Comité de Reactivación Económica (CREN), con miembros del gobierno y la empresa privada, el cual centró su atención en el fomento de las exportaciones no tradicionales. Por esa misma época, el Banco Central de Reserva anunció el establemiento de un fondo de recuperación industrial de 50 millones de dólares, para financiar importaciones de insumos, repuestos y equipos de empresas cuyas exportaciones no tradicionales alcanzarán al menos un $10 \%$ de su producción. Esta línea fue totalmente agotada en un plazo de aproximadamente seis meses. Nos obstante, a finales de 1984 fue robustecida con un nuevo préstamo del BID por 40 milones de dólares, además de recuperaciones de préstamos con los fondos iniciales. 55

Como puede verse, la política económica hacia el sector industrial ha sido totalmente diferente a la practicada con el sector agropecuario. De hecho, el sector industrial ha tenido prioridad en los planes gubernamentales. 


\section{La transformación del sector industrial}

Producto de la crisis global, la industria manufacturera ha sufrido cambios importantes, siendo los más significativos los experimentados en la composición del producto sectorial, y el reforzamiento de algunas de sus características estructurales.

Durante los últimos años, la composición del producto sectorial ha experimentado importantes modificaciones en favor de una mayor participación relativa del subsector agroindustrial. Mientras que en 1978 correspondía a los productos alimenticios, bebidas y tabaco el $53.6 \%$ del valor agregado del sector, en los últimos años la proporción ha aumentado a más del $66.0 \%$. Otros productos importantes de exportación como textiles, calzado, vestuario y productos químicos, experimentaron una pérdida importante de su participación relativa. (Cuadro XIV)

Por otra parte, es importante destacar que en el período posterior a 1978, el componente de materias primas importadas aumentó considerablemente, pasando de un $66.0 \%$ en 1979 a $73.0 \%$ en 1981 , último año de que se disponen cifras. Dentro de este, el coeficiente de importación del subsector agroindustrial aumentó en un $23.0 \%$, lo cual muestra una tendencia hacia una mayor desarticulación entre el sector agropecuario y el industrial, debido fundamentalmente a la fuerte caída de la producción agricola, principalmente café y algodón, lo que ha provocado graves problemas de abastecimiento de insumos internos de las ramas textil y alimenticia.

\section{Cuadro XIV}

El Salvador: Estructura porcentual del valor agregado de la industria manufacturera (1978-1987)

\begin{tabular}{|c|c|c|c|c|c|c|c|c|c|c|}
\hline Ramas & 1978 & 1970 & 1880 & 1881 & 1982 & 1883 & 1984 & 1085 & 1886 & 1807 \\
\hline $\begin{array}{l}\text { Productos alimenticios } \\
\text { Qebidas } \\
\text { Tahaco } \\
\text { Texilles } \\
\text { Calzado } \\
\text { Productos de madera } \\
\text { Muebles } \\
\text { Papel } \\
\text { Impremia } \\
\text { Cuero } \\
\text { Caucho } \\
\text { Productos quiricos } \\
\text { Derivados del petróleo } \\
\text { Minerales no metallcos } \\
\text { Melales baslcos } \\
\text { Productos melálicos } \\
\text { Maquinarla excoplo ele } \\
\text { Maquinarla eléctilca } \\
\text { Equlpo de transponte } \\
\text { Indusirias diversas }\end{array}$ & $\begin{array}{r}35.4 \\
14.2 \\
4.0 \\
5.3 \\
5.1 \\
0.5 \\
2.0 \\
1.9 \\
2.0 \\
0.8 \\
0.4 \\
5.7 \\
6.5 \\
4.0 \\
1.5 \\
1.3 \\
1.4 \\
3.7 \\
0.6 \\
3.6\end{array}$ & $\begin{array}{r}36.4 \\
14.7 \\
4.3 \\
4.8 \\
5.0 \\
0.7 \\
2.3 \\
1.9 \\
2.0 \\
0.8 \\
0.3 \\
4.8 \\
6.7 \\
3.6 \\
1.6 \\
1.2 \\
1.5 \\
3.8 \\
0.5 \\
3.0\end{array}$ & $\begin{array}{r}40.0 \\
16.4 \\
5.0 \\
4.5 \\
3.7 \\
0.7 \\
23 \\
20 \\
2.0 \\
0.8 \\
0.3 \\
2.6 \\
6.0 \\
4.5 \\
1.5 \\
0.7 \\
1.0 \\
3.6 \\
0.2 \\
20\end{array}$ & $\begin{array}{r}41.5 \\
16.8 \\
5.2 \\
4.0 \\
3.9 \\
0.7 \\
2.8 \\
1.8 \\
2.0 \\
0.8 \\
0.3 \\
2.6 \\
5.6 \\
4.4 \\
1.2 \\
0.7 \\
0.9 \\
2.7 \\
0.3 \\
1.7\end{array}$ & $\begin{array}{r}42.6 \\
18.0 \\
5.5 \\
3.0 \\
3.6 \\
0.8 \\
2.7 \\
1.5 \\
1.3 \\
0.8 \\
0.3 \\
3.1 \\
5.7 \\
4.6 \\
1.0 \\
0.7 \\
0.9 \\
2.3 \\
0.2 \\
1.5\end{array}$ & $\begin{array}{r}44.2 \\
15.4 \\
4.7 \\
3.1 \\
3.0 \\
1.5 \\
3.0 \\
1.8 \\
1.3 \\
0.7 \\
0.2 \\
3.5 \\
5.8 \\
4.8 \\
1.2 \\
0.7 \\
1.0 \\
2.4 \\
0.2 \\
1.5\end{array}$ & $\begin{array}{r}46.9 \\
14.4 \\
4.3 \\
2.9 \\
3.1 \\
1.5 \\
2.6 \\
1.6 \\
1.2 \\
0.7 \\
0.2 \\
3.5 \\
5.6 \\
4.3 \\
1.6 \\
0.5 \\
1.0 \\
2.3 \\
0.2 \\
1.5\end{array}$ & $\begin{array}{r}49.2 \\
14.4 \\
3.9 \\
2.4 \\
3.0 \\
1.4 \\
2.0 \\
1.3 \\
1.1 \\
0.5 \\
0.2 \\
3.0 \\
5.3 \\
4.3 \\
1.8 \\
0.5 \\
1.1 \\
2.2 \\
0.2 \\
1.5\end{array}$ & $\begin{array}{r}48.4 \\
14.6 \\
3.9 \\
2.8 \\
.28 \\
1.5 \\
2.7 \\
1.0 \\
1.0 \\
0.4 \\
0.1 \\
3.0 \\
5.2 \\
4.5 \\
2.0 \\
0.4 \\
1.3 \\
2.4 \\
0.2 \\
1.7\end{array}$ & $\begin{array}{r}47.6 \\
14.9 \\
3.8 \\
2.8 \\
.28 \\
1.5 \\
2.8 \\
1.0 \\
1.0 \\
0.4 \\
0.1 \\
3.0 \\
5.3 \\
5.0 \\
2.0 \\
0.4 \\
1.2 \\
2.4 \\
0.2 \\
1.7\end{array}$ \\
\hline Tolal & 100.0 & 100.0 & 100.0 & 100.0 & 100.0 & 100.0 & 100.0 & 100.0 & 100.0 & 100.0 \\
\hline
\end{tabular}

Fuenle: Bunco Centai do Recerva. 
Finalmente, con respecto a una posible diversificación de la producción industrial, no fue posible obtener datos ni evidencias que mostraran el grado de avance del proceso. No obstante, numerosas empresas industriales se han acogido a la Ley de Fomento de Exportaciones, especialmente las dedicadas a la exportación de ropa, calzado y bebidas.

\subsection{El sector externo}

Durante la presente década el sector externo ha sufrido cambios importantes, siendo los más significativos, los producidos con respecto a la inserción dentro de la economía mundial y aquellos relacionados con una incipiente diversifiación de las exportaciones. Dichos cambios están vinculados con la crisis global del país, con el origen del tinanciamiento que ha recibido el país y con la estrategia global de fomento de exportaciones no tradicionales.

\section{Evolución reciente}

La evidencia más clara de la profundidad de la crisis económica del país se manifiesta en el sector externo, y concretamente en la evolución de la balanza comercial. Dicha cuenta que en 1979 mostró un superavit de 92 millones de dólares, se fue deteriorando progresivamente, hasta alcanzar un déficit record de más de 417 millones de dólares en 1987.

Dicho comportamiento se explica básicamente por las exportaciones, las cuales a partir de 1980 experimentan una caida pronunciada, a tal grado que su valor en 1987 fue alrededor de la mitad del obtenido en 1979. Este comportamiento es el resultado de evolución registrada por las exportaciones de café, algodón y las dirigidas al Mercado Común Centroamericano.

En cuanto a las importaciones, como producto del aumento en su valor unitario y del elevado componente importado con que opera el aparato productivo salvadoreño, han permanecido en niveles relativamente altos, to cual ha contribuido a acentuar la brecha comercial.

La situación anterior se ha traducido en una pérdida de la importancia relativa de las exportaciones y las importaciones en la economia nacional. En 1979, dichas cuentas representaban más del $60.0 \%$ del PIB; durante 1987 dicha proporción disminuyó a un $34.0 \%$.

\section{Las principales transformaciones}

Para los propósitos del presente trabajo, nos interesa destacar dos cambios importantes ocufridos durante el período en el sector externo. El primero de ellos se refiere a la forma de inserción de la economía sal- 
vadoreña dentro de la economía mundial; el segundo tiene que ver con el proceso de diversificación de la producción exportable actualmente en marcha.

\title{
El proceso de reinserción de la economía
}

Durante los últimos 9 afios han ocurrido cambios importantes en cuanto al origen y destino del comercio salvadoreño. El hecho más significativo es sin duda la importancia creciente del mercado norteamericano en términos de exportaciones e importaciones, y la pérdida de importancia relativa de otros mercados como el centroamericano, el japonés y el europeo, con la excepción de Alemania. (Cuadro XV)

\author{
Cuadro XV \\ El Salvador: Destino de las exportaciones (1978-1986) \\ (porcentajes)
}

\begin{tabular}{|c|c|c|c|c|c|c|c|c|c|}
\hline Palses & 1978 & 1979 & 1980 & 1981 & 1982 & 1983 & 1984 & 1985 & 1986 \\
\hline Centroamérica & 29.2 & 23.3 & 27.6 & 25.9 & 24.9 & 21.7 & 21.9 & 14.1 & 12.2 \\
\hline Estados Unidos & 21.6 & 26.4 & 41.2 & 25.9 & 35.4 & 33.6 & 37.9 & 47.9 & 49.2 \\
\hline Europa & 31.6 & 39.3 & 20.5 & 36.6 & 32.1 & 33.6 & 262 & 25.9 & 28.7 \\
\hline $\begin{array}{l}\text { Alemania R.F. } \\
\text { Paises bajos }\end{array}$ & 17.1 & 24.4 & 13.9 & 33.0 & 29.3 & 25.9 & 22.5 & 21.0 & 24.1 \\
\hline $\begin{array}{l}\text { (Holanda) } \\
\text { Otros palses }\end{array}$ & 9.0 & 9.5 & 2.7 & 0.9 & 0.3 & 0.3 & 0.1 & 0.1 & 0.2 \\
\hline de Europa & 5.5 & 5.4 & 4.0 & 2.7 & 2.5 & 7.4 & 3.6 & 4.7 & 4.4 \\
\hline Japón & 6.9 & 6.2 & 4.0 & 4.8 & 3.3 & 4.8 & 5.5 & 5.1 & 3.8 \\
\hline Resto del mundo & 10.7 & 4.8 & 6.7 & 6.8 & 42 & 6.3 & 8.5 & 7.1 & 6.2 \\
\hline Total & 100.0 & 100.0 & 100.0 & 100.0 & 100.0 & 100.0 & 100.0 & 100.0 & 100.0 \\
\hline
\end{tabular}

Fuente: Banco Central de Peserva.

En 1978, las exportaciones salvadoreñas dirigidas hacia los Estados Unidos representaron el $21.6 \%$ del total; en 1986, dicha proporción había aumentado a cerca del $50 \%$. Por el contario, las exportaciones hacia el mercado centroamericano y Japón han disminuido significativamente, tanto en términos absolutos como relativos.

Con respecto a Europa, es importante sefialar la importancia creciente de Alemania, y en menor medida de España. Las exportaciones a Alemania han crecido significativamente los últimos años, pasando de representar un $17.0 \%$ del total en 1978 a un $24.0 \%$ en 1986 . Contraria- 
mente, las exportaciones a otros paises como Holanda, han prácticamente desaparecido.

El análisis anterior evidencia el reforzamiento de la dependencia de las exportaciones salvadoreñas del mercado norteamericano y del alemán durante el periodo de crisis. En 1978 las exportaciones a dichos paises representaron en conjunto el $39.0 \%$ del total; en 1986, dicha proporción habia aumentado al $73.0 \%$.

Al igual que las exportaciones, las importaciones procedentes de Estados Unidos han cobrado una importancia creciente, ya que han pasado de representar un $30.0 \%$ del total en 1978 a un $40.0 \%$ en 1986 . (Cuadro XVI). Las otras importaciones que han crecido durante el period son las provenientes de México y de otros paises. Contrariamente, las importaciones de Centroamérica, de Japón, y de Europa han disminuido significativamente.

Cuadro XVI

El Salvador: Origen de las importaciones (1978-1986)

(porcentajes)

\begin{tabular}{lrrrrrrrrr}
\hline \multicolumn{1}{c}{ Paises } & 1970 & 1979 & 1980 & 1981 & 1982 & 1983 & 1984 & 1985 & 1986 \\
\hline Centroamérica & 23.4 & 24.7 & 33.3 & 31.0 & 30.5 & 26.1 & 26.0 & 22.6 & 17.8 \\
Estados Unidos & 30.9 & 27.6 & 20.1 & 25.4 & 27.2 & 31.6 & 33.2 & 33.8 & 39.8 \\
& 16.4 & 16.5 & 10.9 & 15.7 & 14.6 & 13.5 & 11.4 & 12.1 & 12.9 \\
$\begin{array}{l}\text { Europa } \\
\quad \begin{array}{c}\text { Alemania R.F. } \\
\text { Paises bajos }\end{array}\end{array}$ & 15.2 & 4.5 & 2.5 & 3.7 & 4.7 & 4.2 & 4.4 & 4.4 & 4.8 \\
$\begin{array}{l}\text { (Holanda) } \\
\text { Otros palses } \\
\text { de Europa }\end{array}$ & 2.6 & 2.7 & 1.5 & 2.5 & 2.3 & 2.0 & 1.5 & 1.6 & 1.5 \\
Japón & 1.3 & 2.2 & 1.4 & 1.6 & 0.8 & 0.9 & 0.7 & 0.7 & 0.9 \\
$\begin{array}{l}\text { Resto del mundo } \\
11.9\end{array}$ & 17.6 & 3.9 & 3.4 & 3.1 & 3.5 & 4.3 & 5.2 & 3.8 \\
\hline Total & 100.0 & 100.0 & 100.0 & 100.0 & 100.0 & 100.0 & 100.0 & 100.0 & 100.0 \\
\hline
\end{tabular}

Fuente: Banco Central de Reserva.

La evolución mostrada por el comercio salvadoreño con respecto al origen y destino, es comprensible si se toma en cuenta el papel de los Estados Unidos, y en menor medida de Alemania en la crisis salvadorefia. Hemos visto en la primera parte de este trabajo la gran cantidad de recursos económicos proporcionados por Estados Unidos a El Salvador durante la presente década. Dichos recursos generalmente han estado sujetos a una serie de condiciones, entre las cuales destaca la obligación del país de efectuar importaciones procedentes de Estados Unidos. 
Si a ello agregamos el interés de ese pais en reactivar las exportaciones, razón por la cual ha brindado tóoa clase de apoyo y algún tipo de preferencia, se entiende porqué las exportaciones salvadoreñas se han concentrado en el mercado norteamericano.

Por su parte, el incremento de las exportaciones a Alemania se explica por la existencia de tratados comerciales altamente favorables a El Salvador, producto de los estrechos vínculos entre el gobierno demócrata cristiano alemán y su similar salvadorefio.

\section{La diversif́caclón de la oferta exportable}

El segundo fenómeno de importancia acaecido durante la presente década, especialmente a partir de 1984, es la importancia creciente que han experimentado las exportaciones no tradicionales a terceros mercados, especialmente al norteamericano, producto de la incipiente diversificación de la producción exportable del sector agropecuario, y en menor medida del industrial.

Dichas exportaciones son las únicas que han experimentado un crecimiento en términos absolutos y relativos. En términos absolutos, se han incrementado en cerca de un $30 \%$, y en términos relativos casi se han triplicado dentro del total de exportaciones. (Cuadro XI)

Los productos no tradicionales que han tenido mayor dinamismo son los de origen agricola, como es el caso del ajonjolí, legumbres, hortalizas, miel natural, y frutas como melones y sandias (Tabla 3 en Anexo). Como vimos en su oportunidad, estos son precisamente los productos que han incrementado sustancialmente su producción durante los últimos ahos.

Por su parte, los productos industriales que han mostrado más dinamismo son los medicamentos para usos veterinarios, los tejidos de poliester, y el calzado, este último con exportaciones incluso superiores a los 5 millones de dólares. Es importante sefialar que la mayoría de estos productos han sido exportados fundamentalmente a Estados Unidos. (Tabla 4 en Anexo)

Como hemos dicho anteriormente, este proceso de diversificación de la oferta exportable esta todavia en ciernes, y dada la base tan baja de la que parte, los verdaderos resultados se veran más bien en el mediano plazo.

\section{Reflexiones finales}

El análisis de las páginas precedentes evidencia que durante la presente década, la estructura productiva salvadorefia ha experimentado transformaciones importantes que han afectado su composición y su funcionamiento. Dichas transformaciones han sido provocadas, por una 
parte, por los esfuerzos deliberados realizados por Estados Unidos paiprocurar un reordenamiento global de la economia; y por otra, por los efectos de la crisis interna global del pais y de la política económica, especialmente de aquellas medidas dirigidas a contener los desequilibrios macroeconómicos.

La influencia de estos dos tipos de factores ha provocado tansformaciones de signo contario. En efecto, mientras la ejecución del proyecto estructural promovido por Estados Unidos ha dado ya algunos resultados en términos de cierta diversificación de la oferta exportable, de creación de cierta infraestructura física $e$ institucional de apoyo a las actividades de exportación, y aún en términos de cierta ampliación de la base social de apoyo al proyecto; los efectos de la crisis interna global del pais y de la crisis económica han provocado un reforzamiento y una expansión de las principales rigideces estructurales de la economía y una reducción del espacio económico.

Es evidente que el impacto negativo derivado de la crisis interna global y de la política económica adoptada para enfrentarla ha sido mucho mayor que el impacto derivado de la implementación del proyecto de reordenamiento estructural de Estados Unidos. De hecho, los efectos de la crisis interna no sólo han desencadenado la crisis económica y social más grave de la historia del país, sino también han minimizado y aún contrarrestado los posibles efectos positivos que en otras circunstancias hubieran tenido las medidas impulsadas y promovidas por Estados Unidos.

Lo anterior sugiere que la viabilidad de cualquier proyecto de reestructuración global de la economía salvadorena pasa necesariamente por la solución de la crisis interna global del pais, especialmente por la solución del conflicto armado, el cual ha sido y sigue siendo un elemento decisivo en el desencadenamiento y profundización de la crisis salvadoreña.

Notas

1. Para una discusión de la gestación del proyecto exportador de principios de los setenta ver: Menjlvar, Ralael. Crisis del Desarrollismo: Caso El Salvador, EDUCA, Centroamérica, 1977. Su evolución y crisis se discute en: Rosa, Herman. Estados Unidos y Centroamérica en la Década de los Ochenta : La respuesta de política económica, Tesis de Maestrla en Política Económica, Universidad Nacional, Heredia, Costa Rica, Diciembre 1987.

2. Los Informes Complementarios del Ministerio de Hacienda, muestran que en el período 1974-1978 el sector público contrató préstamos extemos por 469 miloones de dólares, correspondiendo el $51 \%$ a infraestructura; $25 \%$ al apoyo del agro, pesca $e$ industria azucarera; y $24 \%$ para la inversión social.

3. Cuando en julio de 1981 El Salvador solicito \$ 36 millones de dólares del fondo de compensaciones del FMI, los palses europeos, exceptuando Italia, se opusieron al 
préstamo por considerar que violaba las nomas y que otorgarlo crearla un serio precedente. No obstante, se aprobó con los votos de Estados Unidos, Canadá, Italia y los palses del Tercer Mundo (que sienpre presionan por condiciones más suaves). Cuando en 1982. El Salvador solicitó un nuevo préstamo, se aprobó sin problemas, aunque las condiciones que se impusieron, fueron suaves comparada a las de Magadascar que habla presentado una solictud más sólida. En el caso del BID, donde Estados Unidos cuenta con el $35 \%$ de los volos, los préstamos por \$ 45 millones de dólares de 1980 para financiar la reforma agraria, se aprobaron pese a la oposición de Canadá, México, Dinamarca y Alemania Occidental, que consideraban que dar ayuda bajo condiciones de guerra civil violaba de la Carta de Constitución del Banco. (Morrel, Jim y Biddle, William. Central America: The Financial War. Internacional Policy Reporte, Washington, marzo de 1983. Resumen publicado en el Boletín de Ciencias Económicas y Sociales, mayo-junio de 1983, San Salvador).

4. En julio 1982, El Salvador firmó un acuerdo Stand-By con el FMl y el primer préstamo de los ochenta con el Banco Mundial, por \$ 65 millones para reconstrucción se dió después del terremoto de 1986.

5. Préstamos "tradicionales" se consideran aquellos destinados a: la comercialización de insumos y produclos agricolas; el desarrollo de la investigación y extensión agrícola; la salud pública y el ambiental (el primero para la construcción de 93 puestos rurales de salud, 15 unidades y 8 centros con 62 camas cada uno; y el segundo, para abastecer agua potable y servicios de letrinización a comunidades rurales); el proyecto hidroeléctrico San Lorenzo; los proyectos de preinversión. (Ver Cuadro III).

6. Nos referimos al préstamo para un proyecto de agua potable y alcantarillado para la zona metropolitana de San Salvador (\$ 172.5 millones), otro para rehabilitar el sistema telefónico (\$5.6 millones), y un tercero, para el distrito de riego y avenamiento Lempa-Acahuapa (\$10.9 millones).

7. La moneda local se genera por la venta de las divisas que ingresan como asistencia directa a balanza de pagos (ESF) y por la venta de alimentos que ingresan bajo el Titulo I de la PL -480 , y que aqui se consideran como apoyo indirecto a la balaza de pagos pues ahorran divisas para importar alimentos.

B. USAID, Congressional Presentation Fiscal Year 1988, Washington, 1988. p. 90.

9. Ibid.

10. bid.p. 89.

11. Ibid. p. 90.

12. USAID, EI Salvador, U. S. Economic Program, 1983.

13. Misión Interagencial del Sistema de Naciones Unidas para el examen y análisis de las pollticas y estrategias de desarrollo rural del Gobiemo de El Salvador. La Pobreza Rural en El Salvador: Elementos Básicos para una Pollitica Campesina. Fotocopia, San Salvador, Enero de 1986.

14. Ibid.

15. Fundación Salvadoreña para el Desarrollo Económico y Social (FUSADES). La Necesidad de un nuevo Modelo Económico para El Salvador - Lineamientos de una Estrategia, San Salvador, 1985.

16. Para una discusión más detallada de la estrategia original véase: Rosa, Herman y Suay Roberto. El Nuevo Modelo Económico Norteamericano para Centroamérica: El caso de El Salvador. Boletin de Ciencias Económicas y Sociales, Universidad Centroamericana José Siméon Cañas, San Salvador. Año IX, No. 1, Enero-Febrero 1986.

17. United States General Accounting Olfice. Foreign Aid: Questions on the Central American Regional Program need to be resolved. Report to the Honorable Patrick Leahy United States Senate. Washington, septiembre 1986. pp. 21-22. 
18. United States Department of State, Agency for Intemational Development, Office of Management and Budget. Report to the President and the Congress: A Plan for Fully Funding the Recomendations of the National Bipartisan Commission on Central America, Special Report No. 162, march 1987. p. 5.

19. Special report 162. Op. Cit. p. 19.

20. Report No. 162. Op. Cit. p. 23.

21. Informe Kissinger. Op. Cit p. 76.

22. Report No. 162. Op. Cit. p. 21.

23. Esta ley contempla entre otras cosas incentivos fiscales, la creación del CENTREX (Centro de trámites de exportación) y la creación del certificado de descuento tributario.

24. Sobresale en este sentido, la ampliación y modernización de la zona franca de San Bartolo y la puesta a disposición de una llnea de crédito con recursos de AID para la construcción de zonas francas privadas en la zona del aeropuerto internacional de Comalapa.

25. Tales como el Bono para el Pronto Reintegro de Divisas y el permiso que tienen los exportadores no tradicionales para abrir cuentas en dólares y vender estas divisas libremente.

26. Reporte No. 162. Op. Cit. p. 89

27. Ibid. p. 90.

28. Ibid.

29. U. S. General Accounting Office. Providing Effective Economic Assitance to EI Salvador and Honduras: A formidable Task. Según carta adjunta en el reporte, este se elaboró en base a una solicitud de abril de 1984 de los senadores Mark $O$. Hattield, Dennis De Concini, Daniel K. Inouye y Patrick Leahy.

30. U. S. General Accounting Office. Op. Cit., pp. 8.

31. Ibid., pp. 8.

32. Ibid., pp. 71-72.

33. Ibid.. pp. 65-67.

34. Ibid.

35. Ibid., pp. 71-72.

36. AID. Policy Paper For the GOES. May 15th, 1984. First Draft.

37. U. S. General Accounting Office. Op. Cit., pp. 52.

38. Ibid., pp. 32.

39. Tal preocupación se hizo manifiesta en una visita que una misión del alto nivel del gobiemo norteamericano hizo al pals el 7 de mayo de 1987 para ponerse en contacto con distintos grupos gubernamentales y a diferencia de anteriores ocasiones también con los partidos de oposición. Los principales miembros de dicha misión eran el subsecretario de defensa (Ikle), el secrelario de asuntos centroamericanos del departamento de Estado (Walker), el encargado de asuntos centroamericanos de AID (Ike), y un miembro del Consejo de Seguridad Nacional (Solorzano).

40. Editorial. Diario El Mundo. 3 de junio de 1987.

41. Special report 162. Op. Cit. p. 11.

42. Para una discusión detallada de esta problemática véase: Rosa, Herman. Estados Unidos y Centroamérica en la Década de los Ochenta: La respuesta de Politica Económica, Tesis de Maestria en Politica Económica, Universidad Nacional, Heredia, Costa Rica, Diciembre 1987.

43. FUSADES, Boletín Económico y Social, No. 14, Agosto 1986, San Salvador. p. 3.

44. Ver Boletin de FUSADES No. 23, mayo de 1987.

45. La plataforma es reproducida en la revista UCA, Universidad Centroamericana José Simeón Cañas, San Salvador, Noviembre-Diciembre 1988.

46. BID, El Salvador: Inlorme Socioeconómico, Mimeo, Junio 1987.

47. Ibid. 
48. AID, Profitability of Colton Production under Alternative Guarantee Prices. San Salvador, Mayo 1984.

49. Ministerio de Planificación. Polliticas Sectoriales de Producción Subsector Calé, San Salvador, 1986.

50. Pino Cáceres, José Eduardo. Crisis Estructural de la Caficultura Salvadoreña. Una Hipótesis Alarmante, Revista Presencia, CENITEC, Año 1, Número 1, San Salvador. Abril-Junio 1988.

51. PERA-MAG, VII Evaluación de la Reforma Agraria, San Salvador, 1987.

52. Ibid.

53. Según estadlsticas del MAG, las importaciones de hortalizas como sandias, rábanos, gũisquiles y ejotes y otros han dismimuidos significativamente durante los últimos años.

54. Durante el perlodo comprendido entre junio de 1979 y diciembre de 1983 hubo un total de 243 empresas cerradas, de las cuales 102 pertenecian al sector manufacturero. (Ministerio de Planificación, Diagnóstico del Sector Industrial, Inédito, San Salvador, 1985). Por otra parte, la inversión en equipos correspondiente a la lotalidad del sector se redujo de unos 147 millones de dólares en 1978, a un promedio de 33 millones en 1982-1983. El valor total de la importación de equipos autorizada en 1985 fue de apenas 14 millones de dólares. De esa relación, y de otra elaborada por el Ministerio de Economla, resulta que sólo una docena de empresas aproximadamente, importaron equipos por más de 500,000 dólares en 1982-1985. (Ministerio de Planificación, Diagnóstico., Op. Cit.)

55. Ministerio de Planiricación, Diagnóstico., Op. Cit. 


\section{Anexos Estadisticos}

Tabla No. 1

El Salvador: Destino por proyecto de la asistencia económica compromelida por AID

(Años Fiscales de Estados Unidos y Miles de dólares)

\begin{tabular}{|c|c|c|c|c|c|c|c|c|c|c|c|}
\hline Título del Proyecto & No. & 1980 & 1981 & 1982 & 1983 & 1984 & 1985 & 1986 & 1987 & 1988 & total \\
\hline $\begin{array}{l}\text { Apoyo a balanza de pagos } \\
\text { Apoyo y desarrollo de programas }\end{array}$ & d & 3000 & 62000 & 127300 & 159000 & 149000 & 274000 & 191000 & $\begin{array}{r}241185 \\
1000\end{array}$ & 199500 & $\begin{array}{r}1405985 \\
1000\end{array}$ \\
\hline Apoyo al sector privado I & d267 & & 20000 & 100000 & 120000 & 100000 & 65000 & & & & 405000 \\
\hline Apoyo al sector privado II & p274 & & 24900 & & & & & & & & 24900 \\
\hline Apoyo a la balanza de pagos & d310 & & & & & & 160000 & 30000 & & & 190000 \\
\hline Apoyo a la balanza de pagos AF 86 & d328 & & & & & & & 117000 & 197000 & 164500 & 478500 \\
\hline Costo apoyo local & d & & & & & & & & 1185 & & 1185 \\
\hline$P L-480$ Titulo 1 & $\mathbf{p}$ & 3000 & 17100 & 27300 & 39000 & 49000 & 49000 & 44000 & 42000 & 35000 & 305400 \\
\hline Restauración serviclos públlcos & & 1500 & 0 & 13400 & 14600 & 5000 & 25000 & 20000 & 20000 & 19000 & 118500 \\
\hline Restauración Serv. públicos & d279 & & & & 14600 & 5000 & 25000 & 20000 & 20000 & & 84600 \\
\hline Restauración Serv. Públicos & p279 & & & 13400 & & & & & & & 13400 \\
\hline Restauración Serv. Públicos & d320 & & & & & & & & & 19000 & 19000 \\
\hline Planlf. de polítlca económica & $d 260$ & 900 & & 450 & 1000 & 1250 & 1370 & 2282 & 2203 & 1000 & 10455 \\
\hline Sublotal estabilización económica & & 5400 & 62000 & 141150 & 174600 & 155250 & 300370 & 213282 & 263388 & 219500 & 1534940 \\
\hline Desastre, vivlenda, desplazados & & 9119 & 17557 & 14153 & 26215 & 15410 & 41348 & 14540 & 169478 & 11904 & 319724 \\
\hline Asistencia p/desastre, terremoto & $d$ & 25 & 2355 & 256 & & & & & 151442 & & 154078 \\
\hline Asistencia P/desastre, (vivienda) & d288 & & & 210 & & & & & & & 210 \\
\hline Programa comunidades marginales & $d 251$ & 825 & 125 & & & & & & & & 950 \\
\hline Programa comunidades marginales & p251 & 5000 & 6000 & & & & & & & & 11000 \\
\hline Vivienda de emerg. p/desplazados & d299 & & & & 210 & 75 & & & & & 285 \\
\hline
\end{tabular}




\begin{tabular}{|c|c|c|c|c|c|c|c|c|c|c|c|}
\hline $\begin{array}{l}\text { Prog. de emerg. p/desplazados } \\
\text { Planificación de vivienda urbana } \\
\text { Organismos privados voluntarios } \\
\text { PL-480 Titulo II }\end{array}$ & $\begin{array}{l}\text { d281 } \\
\text { dReg } \\
d \\
d\end{array}$ & 3269 & 9077 & 7687 & 21480 & $\begin{array}{r}10000 \\
35 \\
5300\end{array}$ & 3638 & 5870 & $\begin{array}{l}9750 \\
2666\end{array}$ & $\begin{array}{l}1000 \\
5904\end{array}$ & $\begin{array}{r}77525 \\
35 \\
10750 \\
64891\end{array}$ \\
\hline $\begin{array}{l}\text { Empleo y programas especlales } \\
\text { Empleo en sector público } \\
\text { Empleo en sector público } \\
\text { Apoyo y desarrollo proyectos. ASD } \\
\text { Actividades desarrollo especiales }\end{array}$ & $\begin{array}{l}\text { d256 } \\
\text { p256 } \\
\text { d177 } \\
\text { d094 }\end{array}$ & $\begin{array}{r}14215 \\
125 \\
14000 \\
40 \\
50\end{array}$ & $\begin{array}{r}13707 \\
13430 \\
202 \\
75\end{array}$ & $\begin{array}{r}13491 \\
530 \\
12500 \\
461\end{array}$ & $\begin{array}{l}200 \\
350\end{array}$ & $\begin{array}{l}535 \\
350\end{array}$ & $\begin{array}{r}2498 \\
350\end{array}$ & $\begin{array}{r}2365 \\
350\end{array}$ & $\begin{array}{r}2347 \\
350\end{array}$ & $\begin{array}{r}1275 \\
350\end{array}$ & $\begin{array}{r}53033 \\
955 \\
39930 \\
9923 \\
2225\end{array}$ \\
\hline $\begin{array}{l}\text { Salud } \\
\text { Apoyo/desarrollo programas salud } \\
\text { Salud (OPG) } \\
\text { Salud } \\
\text { Salud y nutrición } \\
\text { Revitalización sistema salud I } \\
\text { Revitalización sistema salud I } \\
\text { Mejora gestión sistemas de salud } \\
\text { Fortal. serv. rehabilitación } \\
\text { Promoción salud matemo-inlantil } \\
\text { Agua potable/sanidad ambiental } \\
\text { Organismos privados voluntarios }\end{array}$ & $\begin{array}{l}\text { d178 } \\
\text { d273 } \\
\text { d178 } \\
\text { d253 } \\
\text { d291 } \\
\text { p291 } \\
\text { d308 } \\
\text { d330 } \\
\text { d } \\
\text { d318 } \\
d\end{array}$ & $\begin{array}{r}896 \\
49 \\
22 \\
825\end{array}$ & $\begin{array}{r}455 \\
5 \\
450\end{array}$ & $\begin{array}{l}27 \\
27\end{array}$ & $\begin{array}{r}1275 \\
15500\end{array}$ & $\begin{array}{r}6085 \\
85\end{array}$ & $\begin{array}{r}13850 \\
1020\end{array}$ & $\begin{array}{r}14900 \\
280 \\
220\end{array}$ & $\begin{array}{r}9178 \\
374\end{array}$ & $\begin{array}{r}5000 \\
500\end{array}$ & $\begin{array}{r}81656 \\
3001 \\
49 \\
22 \\
1275 \\
12225 \\
23380 \\
35204 \\
280 \\
220 \\
5000 \\
1000\end{array}$ \\
\hline $\begin{array}{l}\text { Eduación } \\
\text { Apoyo/desarrollo prog. Educativo } \\
\text { Fondo p/educación en extranjero } \\
\text { Revitalización sistema educativo } \\
\text { Organismos privados voluntarios }\end{array}$ & $\begin{array}{l}d 168 \\
d 223 \\
d 295 \\
d\end{array}$ & 0 & 0 & $\begin{array}{r}146 \\
146\end{array}$ & $\begin{array}{r}297 \\
62 \\
235\end{array}$ & $\begin{array}{l}284 \\
175 \\
109\end{array}$ & $\begin{array}{r}9125 \\
400 \\
8725\end{array}$ & $\begin{array}{r}16040 \\
840 \\
15200\end{array}$ & $\begin{array}{r}5314 \\
2250 \\
2689 \\
375\end{array}$ & $\begin{array}{r}7394 \\
469 \\
6925\end{array}$ & $\begin{array}{r}38600 \\
4196 \\
490 \\
33539 \\
375\end{array}$ \\
\hline $\begin{array}{l}\text { Planificaclón de pobiaclón } \\
\text { Planificación lamiliar y poblac. }\end{array}$ & d149 & $\begin{array}{l}933 \\
933\end{array}$ & $\begin{array}{l}1766 \\
1766\end{array}$ & $\begin{array}{l}1780 \\
1730\end{array}$ & 1850 & 1944 & 6225 & 6673 & 1286 & 1100 & $\begin{array}{r}23557 \\
4429\end{array}$ \\
\hline
\end{tabular}


Asoc. Demográfica Salvadoreña

Dinámica de población

Apoyo/des. programa población

Reforma judicial y política

Relorma judicial

Observadores a elecciones

Elecciones salvadoreñas

Fortalecimiento gob. local

Subtotal establlizaclón social

Reforma agraria

Organi. y capac. p/reforma agraria

Sindicatos rel. agraria (AIFLD)

Sindicatos ref. agraria (AIFLD)

Sindicatos ref. agraria (AIFLD)

Sindicatos ref. agraria (AIFLD)

Asist Técnica Technoserve, OPG

Asist Técnica Technoserve, OPG

Asist Técnica Technoserve, OPG

Créditos de la Reforma Agraria

Créditos de la Reforma Agraria

Apoyo a la refoima agraria

Apoyo al sector reformado

Financiamiento para ref. agraria

Apoyo y desarrollo proyectos ARDN

Sector privado exportador

Recuperación industrial

Capact p/desarr. sector privado
Apoyo al sector reformado

d275

d210

I d181

d296

dPeg

d293

d

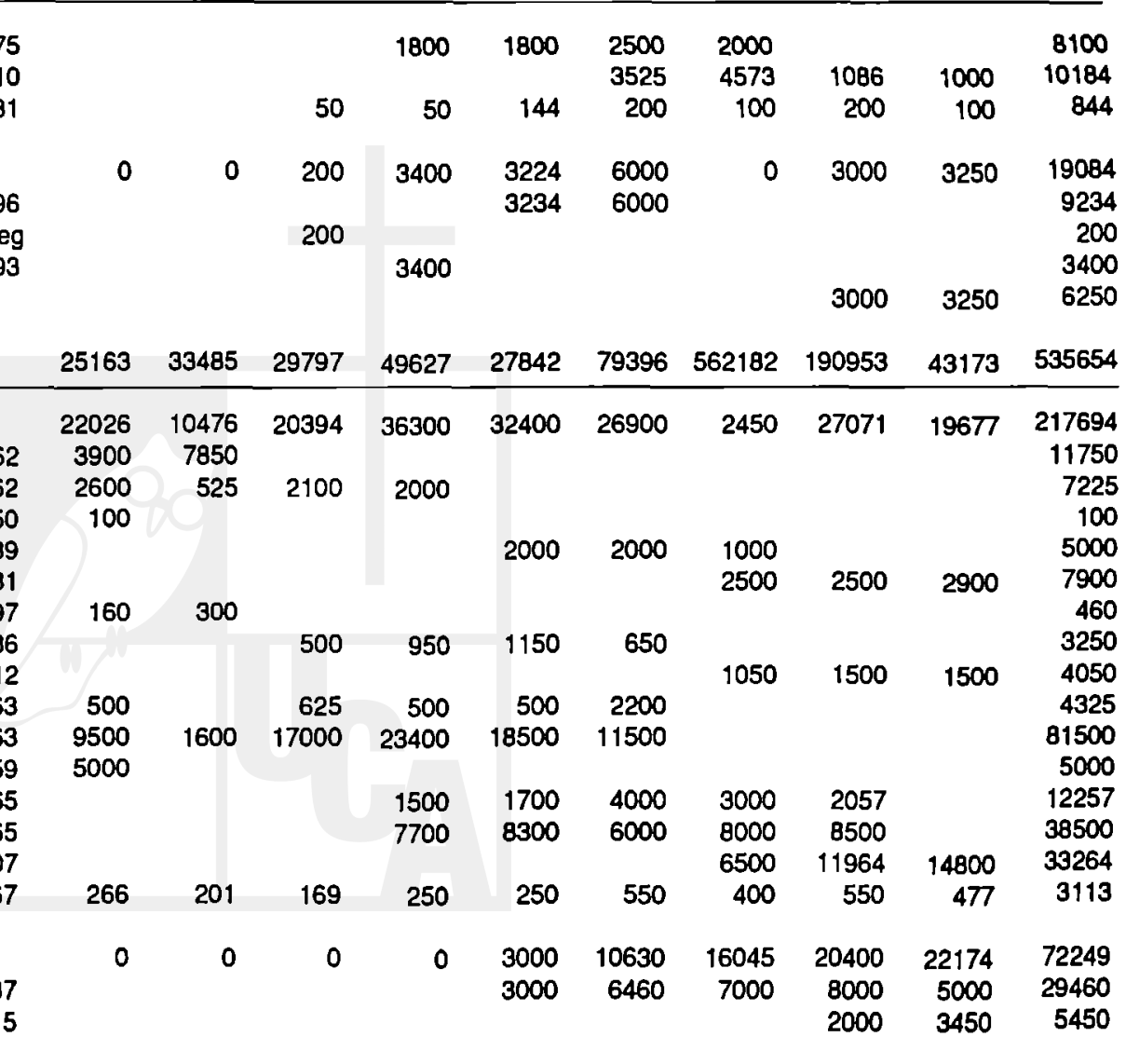

Digitalizado por Biblioteca "P. Florentino Idoate, S.J."

Universidad Centroamericana José Simeón Cañas 
Empresarios Juveniles OPG

Fortalecimiento FUSADES

Manejo de recursos acuiferos

Desartollo de "agribusiness"

Parques industriales/infraestruct.

Parques industriales/infraestruct.

Pequefía empresa y desarrollo rural

Desarrollo pequeño productor

Desarrollo pequeño productor

Corp. Int. servicios ejecutivos

Pequeña empresa urbana, OPG

Asistencia a la pequeña empresa

Asistenica a la pequeña empresa

Centro Producción El Castaño OPG

Programa Save the Children (OPG)

Programa Save the Children

\section{Educación p/el cambio}

Iniciativas de capacitación LAC

Capacitación regional LAC

Programa Becas p/la paz en C.A. d311

d316

d303

d327

d323

p323

Subtotal transformación estructural

Totales por año fiscal

\begin{tabular}{|c|c|c|c|c|c|c|c|c|c|c|}
\hline p229 & $\begin{array}{l}5960 \\
5000\end{array}$ & 263 & $\begin{array}{l}1510 \\
1000\end{array}$ & $\begin{array}{l}1000 \\
1000\end{array}$ & $\begin{array}{l}4235 \\
4000\end{array}$ & $\begin{array}{l}8100 \\
1000\end{array}$ & 2800 & 1800 & 6500 & $\begin{array}{r}32168 \\
8000\end{array}$ \\
\hline d229 & 500 & 125 & 125 & & & 5000 & & & & 9750 \\
\hline d302 & & & & & & 500 & & & & 500 \\
\hline d304 & & & & & & 1000 & 1000 & & 1000 & 3000 \\
\hline d322 & & & & & & & 500 & 500 & & 1000 \\
\hline d318 & & & & & & & & & 5000 & 5000 \\
\hline d222 & 200 & 138 & 142 & & & & & & & 480 \\
\hline d215 & 260 & & 243 & & 235 & & & & & 738 \\
\hline d300 & & & & & & 600 & 1300 & 1300 & 500 & 3700 \\
\hline \multirow{5}{*}{$\begin{array}{l}\text { dReg } \\
\text { dReg } \\
\text { dReg }\end{array}$} & 0 & 25 & 375 & 350 & 350 & 3400 & 6900 & 4700 & 5500 & 21600 \\
\hline & & 25 & 350 & 350 & 350 & & & & & 1075 \\
\hline & & & & & & 3400 & 6900 & 4700 & 5500 & 20500 \\
\hline & 27986 & 10764 & 22279 & 37650 & 39985 & 49030 & 48195 & 53971 & 53851 & 343711 \\
\hline & 58549 & 06249 & 193226 & 261877 & 223077 & 428796 & 317695 & 508312 & 316524 & 2414305 \\
\hline
\end{tabular}

Fuente: 1. 1980-1983: Hernández Ramos, Rigoberto et. al. La politica Exterior norteamericana y su incidencia en la economla de El Salvador Tesis UCA, San Salvador, julio 1986. 2. 1984-1985: AID, El Salvador - US Economic Asistance Program, Enero 1987. 3. 1986-1988, AID, Congresssional Presentation Fiscal Year 1988.

NOTAS: LOS datos de 1987 son estimaciones y los de 1988 corresponden a solicitud de Administración. En 1986 se incluyó la parte correspondiente al programa de Becas para la Paz según tuente 2.

Digitalizado por Biblioteca "P. Florentino Idoate, S.J."
Universidad Centroamericana José Simeón Cañas 
Tabla No. 2

Producto territorial bruto del sector agropecuario (particlpación relativa)

\begin{tabular}{|c|c|c|c|c|c|c|c|c|c|}
\hline & 1978 & 1080 & 1981 & 1982 & 1893 & 1084 & 1885 & 1886 & 1887 \\
\hline $\begin{array}{l}\text { griculhura } \\
\text { roductos principales }\end{array}$ & $67.93 \%$ & $69.01 \%$ & $68.30 \%$ & $67.99 \%$ & $67.56 \%$ & $65.99 \%$ & $64.69 \%$ & $61.94 \%$ & $62.44 \%$ \\
\hline $\begin{array}{l}\text { de exportacion } \\
\text { Calé } \\
\text { algodón } \\
\text { calla de azúcar }\end{array}$ & $\begin{array}{c}44.27 \% \\
33.21 \% \\
7.86 \% \\
3.20 \%\end{array}$ & $\begin{array}{r}45.32 \% \\
34.77 \% \\
7.94 \% \\
260 \%\end{array}$ & $\begin{array}{r}43.10 \% \\
34.70 \% \\
5.96 \% \\
2.45 \%\end{array}$ & $\begin{array}{r}44.56 \% \\
36.11 \% \\
5.74 \% \\
2.70 \%\end{array}$ & $\begin{array}{r}42.93 \% \\
33.34 \% \\
6.04 \% \\
3.55 \%\end{array}$ & $\begin{array}{r}39.25 \% \\
30.87 \% \\
4.51 \% \\
3.87 \%\end{array}$ & $\begin{array}{r}38.87 \% \\
31.10 \% \\
3,80 \% \\
397 \%\end{array}$ & $\begin{array}{r}36.10 \% \\
29.82 \% \\
1,95 \% \\
4.34 \%\end{array}$ & $\begin{array}{r}35.80 \% \\
30.25 \% \\
1.80 \% \\
3.75 \%\end{array}$ \\
\hline $\begin{array}{l}\text { Granas basicos } \\
\text { malz } \\
\text { injol } \\
\text { aroz } \\
\text { maldllo }\end{array}$ & $\begin{array}{r}14.88 \% \\
9.19 \% \\
1.94 \% \\
1.77 \% \\
1.98 \%\end{array}$ & $\begin{array}{r}15.25 \% \\
9.78 \% \\
1.72 \% \\
1.93 \% \\
1.82 \%\end{array}$ & $\begin{array}{r}15.33 \% \\
9.93 \% \\
1.80 \% \\
1.70 \% \\
1.89 \%\end{array}$ & $\begin{array}{r}13.55 \% \\
6.59 \% \\
1.88 \% \\
1.27 \% \\
1.81 \%\end{array}$ & $\begin{array}{r}15.08 \% \\
9.49 \% \\
2.15 \% \\
1.60 \% \\
1.84 \%\end{array}$ & $\begin{array}{r}17.64 \% \\
10.95 \% \\
2.40 \% \\
2.25 \% \\
2.05 \%\end{array}$ & $\begin{array}{r}16.52 \% \\
10.38 \% \\
1.71 \% \\
2.48 \% \\
1.95 \%\end{array}$ & $\begin{array}{r}\mathbf{1 6 . 0 3 \%} \\
\mathbf{9 . 4 6 \%} \\
\mathbf{2 . 5 6 \%} \\
1.97 \% \\
\mathbf{2 . 0 4 \%}\end{array}$ & $\begin{array}{r}1721 \% \\
10.29 \% \\
2.72 \% \\
211 \% \\
2.10 \%\end{array}$ \\
\hline $\begin{array}{l}\text { Ovos productos agricolas } \\
\text { panala } \\
\text { lahaco } \\
\text { semilla de algodon } \\
\text { henequen } \\
\text { kenal } \\
\text { orros y/ }\end{array}$ & $\begin{array}{l}8.78 \% \\
0.09 \% \\
0.57 \% \\
1.43 \% \\
0.46 \% \\
0.05 \% \\
6.17 \%\end{array}$ & $\begin{array}{l}0.44 \% \\
0.10 \% \\
0.77 \% \\
0.96 \% \\
0.50 \% \\
0.06 \% \\
6.05 \%\end{array}$ & $\begin{array}{l}9.87 \% \\
0.10 \% \\
0.90 \% \\
0.98 \% \\
0.65 \% \\
0.05 \% \\
7.18 \%\end{array}$ & $\begin{array}{l}9.88 \% \\
0.11 \% \\
0.93 \% \\
0.95 \% \\
0.83 \% \\
0.07 \% \\
7.01 \%\end{array}$ & $\begin{array}{l}9.55 \% \\
0.11 \% \\
1.06 \% \\
0.98 \% \\
0.85 \% \\
0.07 \% \\
6.48 \%\end{array}$ & $\begin{array}{l}9.09 \% \\
0.11 \% \\
0.99 \% \\
0.63 \% \\
0.84 \% \\
0.08 \% \\
0.46 \%\end{array}$ & $\begin{array}{l}9.30 \% \\
0.11 \% \\
1.05 \% \\
0.55 \% \\
0.77 \% \\
0.08 \% \\
6.74 \%\end{array}$ & $\begin{array}{l}9.81 \% \\
0.11 \% \\
1.00 \% \\
0.32 \% \\
0.78 \% \\
0.10 \% \\
7.50 \%\end{array}$ & $\begin{array}{l}9.42 \% \\
0.11 \% \\
0.94 \% \\
0.30 \% \\
0.65 \% \\
0.12 \% \\
7.31 \%\end{array}$ \\
\hline Ganaderla & $14.87 \%$ & $13.14 \%$ & $1278 \%$ & $11.72 \%$ & $10.98 \%$ & $12.17 \%$ & $12.94 \%$ & $13.98 \%$ & $14.00 \%$ \\
\hline Silvieultura & $3.26 \%$ & $3.15 \%$ & $3.49 \%$ & $3.68 \%$ & $3.87 \%$ & $3.76 \%$ & $3.86 \%$ & $4.04 \%$ & $3.91 \%$ \\
\hline Pesca & $1.41 \%$ & $1.56 \%$ & $1.44 \%$ & $1.65 \%$ & $1.50 \%$ & $2.29 \%$ & $2.02 \%$ & $2.36 \%$ & $222 \%$ \\
\hline Aplathura & $0.17 \%$ & $0.20 \%$ & $0.28 \%$ & $0.29 \%$ & $0.34 \%$ & $0.35 \%$ & $0.42 \%$ & $0.47 \%$ & $0.46 \%$ \\
\hline Avicultura & $1236 \%$ & $1294 \%$ & $13.72 \%$ & $14.67 \%$ & $15.75 \%$ & $15.42 \%$ & $16.07 \%$ & $1720 \%$ & $16.98 \%$ \\
\hline Total & $100.0 \%$ & $100.00 \%$ & $100.00 \%$ & $100.00 \%$ & $100.00 \%$ & $100.00 \%$ & $100.00 \%$ & $100.00 \%$ & $100.00 \%$ \\
\hline
\end{tabular}

Fuentes: Bunco Contral de Resorve de $\mathrm{E}$ Selvador.

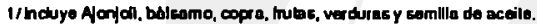


Tabla No. 3

El Salvador

Principales productos no tradiclonales exportados hacla terceros mercados durante el perlodo 1980/1987

(Valor en millones de colones)

\begin{tabular}{|c|c|c|c|c|c|c|c|c|}
\hline Producto & 1890 & 1881 & 1892 & 1993 & 1904 & 1885 & 1886 & 1937 \\
\hline Las demás semplas oleaglnosas (ajonjoli) & $\mathbf{3}$ & $\mathbf{5}$ & 1 & 3 & 12 & 18 & 21 & 27 \\
\hline Acoltes pesados y lubricamios & 14 & 19 & B & 16 & 20 & 15 & 29 & 19 \\
\hline Betún de peróleo & - & - & - & - & - & - & - & - \\
\hline Oros modicamenlos p'velertnarla & - & 3 & 3 & 11 & 22 & 4 & 13 & 19 \\
\hline Jabones tocador, shampoos y otros jabones medkinales & 3 & 2 & 2 & 1 & $\mathbf{9}$ & - & 2 & 1 \\
\hline Incediddas & 3 & 2 & 2 & 2 & 7 & $\mathbf{3}$ & 5 & 5 \\
\hline Cajas, sacos y oros anvases de papel cartón & - & - & 1 & 4 & 2 & 2 & 4 & 6 \\
\hline Hilados de algodón sin acondiclonador & - & - & 12 & 12 & 12 & 6 & 10 & 7 \\
\hline Hillados do algodón acondktonados & 10 & 7 & 3 & 5 & 30 & B & 17 & 14 \\
\hline Telidos de pollester & 1 & - & - & - & 16 & 7 & 26 & 11 \\
\hline Otros tepldos de fibras textiers & - & - & 1 & 8 & 21 & 6 & 6 & - \\
\hline Otros tej/dos de fibras antildales discontnuas & - & - & - & - & 8 & - & B & - \\
\hline Tęlidos de punto no elásillos & - & - & - & - & 15 & - & 6 & - \\
\hline Los demás cemento blanco & - & 1 & - & $\theta$ & 6 & - & - & - \\
\hline Hojas y thras delgadas de aluminlo & 1 & 1 & 1 & - & 23 & 12 & - & - \\
\hline Otros hillos alambres de cobre & - & 1 & - & - & 10 & - & - & - \\
\hline calzado de suela de cuero natural & - & - & - & - & 10 & 5 & 17 & 28 \\
\hline calzado con plso de otras materias & - & - & - & - & 6 & - & 6 & - \\
\hline Laplicos para escriblr & - & - & - & - & - & - & 1 & 1 \\
\hline Otros malces & - & - & - & - & - & B & - & - \\
\hline Legurbies, hortalizas y Irura conservada en vinagre & 2 & 2 & 1 & 4 & - & 5 & 10 & 16 \\
\hline Sucedaneos que contengan calé y oros, calés & 21 & 14 & 8 & 13 & - & - & 42 & 11 \\
\hline Las demás semillas & - & - & 1 & - & - & - & 7 & 3 \\
\hline Mlel natural (mlel de abejas) & 5 & $\mathbf{5}$ & 6 & 6 & 5 & $\mathbf{3}$ & 10 & 9 \\
\hline Melones y sandlas (demas Irulas Irescas) & 2 & - & - & - & - & - & 6 & 11 \\
\hline Bormbones, dulces, caramelos, etc. & 2 & - & - & 1 & - & - & - & - \\
\hline Tabacos en rama & - & 2 & - & 2 & - & - & - & - \\
\hline Azulre de cualquler clase & - & - & - & - & - & - & - & 15 \\
\hline Bâlsanto & 6 & 6 & 4 & 3 & - & - & 6 & $\mathbf{g}$ \\
\hline Aloohol etllies & - & - & - & - & - & - & 6 & - \\
\hline Prendas exteriores para mujer, ninos & - & - & - & - & - & - & 6 & 7 \\
\hline Ropa de cama & - & 1 & 1 & - & - & - & - & $\ldots$ \\
\hline Otras suelas, laconosy capelladas & - & - & - & - & - & - & - & 5 \\
\hline Raspadores de coco & 2 & 1 & 1 & - & - & - & - & - \\
\hline Toallas, toallitas, de euajquler Ibra textil del algodón & 11 & 14 & 15 & - & - & - & - & - \\
\hline Macheles & 1 & 1 & 2 & - & - & 2 & - & - \\
\hline
\end{tabular}

Fuenle: 1980/1983 anuorios estedistoos digestyc $1984 / 1987$ Nieo 
Tabla No. 4

El Salvador

Principales exportaclones hacla los Estados Unidos. Valor CIF (En millones de dólares)

\begin{tabular}{|c|c|c|c|c|c|}
\hline & 1983 & 1984 & 1985 & 1986 & 1987 \\
\hline Total exportado & 373.6 & 397.1 & 413.3 & 386.3 & 288.6 \\
\hline Café. & 212.6 & 201.1 & 254.8 & 271.5 & 162.2 \\
\hline Mariscos frescos, congelados, salados. & 18.2 & 25.4 & 21.1 & 23.9 & 26.6 \\
\hline Aparatos y maquinaria eléctrica. & 22.5 & 25.8 & 18.4 & 18.9 & 26.2 \\
\hline Abrigos de lana, algodón. & 4.5 & 4.1 & 6.7 & 8.8 & 18.6 \\
\hline Hilos e hilazas, textiles. & 2.8 & 5.5 & 3.0 & 7.7 & 9.5 \\
\hline Articulos hechos de material textil. & 4.7 & 2.9 & 4.7 & 5.0 & 5.5 \\
\hline Calzado nuevo, excepto militar. & 0.7 & 0.9 & 1.9 & 3.3 & 5.0 \\
\hline Frutas y nueces. & 0.8 & 1.4 & 1.8 & 3.9 & 4.7 \\
\hline Vegetales frescos, legumbres secas. & 1.3 & 1.8 & 2.6 & 2.8 & 3.8 \\
\hline Came fresca, frla o congelada. & 3.9 & 3.8 & 3.0 & 2.3 & 3.2 \\
\hline Ropa interior, tejida de punto. & 2.1 & 2.2 & 2.6 & 2.1 & 2.7 \\
\hline Semillas y frutas oleaginosas. & 0.6 & 1,6 & 2.9 & 1.9 & 2.6 \\
\hline Papel y carton cortado. & 0.5 & 0.6 & 0.8 & 1.2 & 2.6 \\
\hline Instrumentos y utencilios médicos. & 4.0 & 3.9 & 6.2 & 2.9 & 1.8 \\
\hline Transacciones especiales, NSPF. & 1.6 & 2.1 & 3.0 & 3.3 & 1.5 \\
\hline Sudaderas y accesorios textiles. & 0.0 & 0.1 & 0.2 & 0.2 & 1.4 \\
\hline Coches para niños, jugueles. & 0.7 & 0.6 & 0.9 & 0.9 & 1.1 \\
\hline Camisas. & 0.0 & 0.8 & 1.1 & 0.3 & 1.1 \\
\hline Pescado fresco, frío y congelado. & 0.2 & 0.1 & 0.4 & 1.0 & 1.0 \\
\hline Materiales vegetales, NSPF. & 0.8 & 0.8 & 0.6 & 0.5 & 0.9 \\
\hline Tela, algodón, tejidos, excepto especif. & 0.1 & 0.4 & 0.4 & 0.8 & 0.7 \\
\hline Resina sintética, hule y plástico. & 0.0 & 0.0 & 0.4 & 0.6 & 0.6 \\
\hline Partidas con menos de $\$ 251$ exportadas & 0.3 & 0.3 & 1.0 & 1.1 & 0.5 \\
\hline Papel y carton no cortados. & 0.0 & 0.0 & 0.0 & 0.0 & 0.4 \\
\hline Muebles y sus partes componentes. & 0.1 & 0.1 & 0.1 & 0.3 & 0.4 \\
\hline Metales preciosos, minerales concentrados. & 0.0 & 0.4 & 0.3 & 0.4 & 0.4 \\
\hline Bebidas alcohólicas. & 0.1 & 0.2 & 0.2 & 0.3 & 0.3 \\
\hline Articulos de hule y plástico & 0.8 & 1.8 & 0.4 & 0.4 & 0.3 \\
\hline Manufacturas de madera, no especif. & 0.0 & 0.1 & 0.1 & 0.2 & 0.3 \\
\hline Ropa exterior, camiselas. & 0.0 & 0.3 & 0.7 & 0.2 & 0.3 \\
\hline Manufacturas de cuero, NSPF. & 0.0 & 0.4 & 0.1 & 0.1 & 0.2 \\
\hline Azúcar, jarabe, melaza. & 33.9 & 30.8 & 27.4 & 12.3 & 0.2 \\
\hline Derperdicios y desechos no ferrosos. & 0.2 & 0.0 & 0.0 & 0.0 & 0.2 \\
\hline Jabon incluso en polvo. & 0.0 & 0.0 & 0.1 & 0.3 & 0.2 \\
\hline Pescado seco, salado, encurtido. & 0.0 & 0.0 & 0.0 & 0.0 & 0.1 \\
\hline Equipo eléctrico, cargadores eléctricos, resist. & 0.0 & 0.0 & 0.0 & 0.0 & 0.1 \\
\hline Componentes y respuestos electrónicos. & 52.0 & 70.4 & 40.5 & 0.9 & 0.1 \\
\hline Materiales de construcción (arcilla). & 0.0 & 0.0 & 0.0 & 0.1 & 0.1 \\
\hline Articulos manolacturados, NSPF. & 0.0 & 0.2 & 0.0 & 0.0 & 0.1 \\
\hline $\begin{array}{l}\text { Total de productos principales. } \\
\text { Resto de produotos. }\end{array}$ & $\begin{array}{r}370.4 \\
3.2\end{array}$ & $\begin{array}{r}391.2 \\
5.9\end{array}$ & $\begin{array}{r}408.6 \\
4.7\end{array}$ & $\begin{array}{r}308.9 \\
5.4\end{array}$ & $\begin{array}{r}287.6 \\
0.9\end{array}$ \\
\hline
\end{tabular}

Fuente: Estadlelicas Oiliales del Departamento de Comerclo de Estados Unides. 1987. 